\title{
Unidad Campesina del MIR durante la Unidad Popular chilena: memorias subalternas desde la militancia revolucionaria, femenina y local ${ }^{*}$
}

\author{
Peasant organization during the Chilean Popular Unity: subaltern memories \\ from the revolutionary militancy, feminine and local
}

\author{
María Angélica Cruz Contreras ${ }^{* *}$ Erick Fuentes Góngora ${ }^{* * *}$
}

\begin{abstract}
Resumen: El artículo describe, desde un relato de vida, los inicios de la trayectoria política de una militante del Movimiento de Izquierda Revolucionaria (MIR), a partir de su participación en una unidad campesina del Movimiento Campesino Revolucionario (MCR) en los Andes y Quillota (Valparaíso) en el marco de la Reforma Agraria impulsada por la Unidad Popular chilena (1970-1973). La reconstrucción de esta trayectoria ilustra cómo en el ingreso al MIR influyen los legados familiares, la reforma universitaria y la inserción en el campo de una estudiante en práctica. A su vez, el análisis de la forma en que se reconstruye este relato contribuye a comprender cómo operan memorias sociales sobre el pasado reciente en Chile triplemente subalternas: las memorias militantes, femeninas y locales.
\end{abstract}

Palabras Claves: memoria social, género, militancia, unidad campesina, Movimiento Campesino Revolucionario, Movimiento de Izquierda Revolucionaria

Abstract: Based on a life history interview, this paper describes the beginning of a
woman's political trajectory, as a part of Movimiento de Izquierda Revolucionaria
(MIR, spanish for Revolutionary Left-wing Movement) since she was first involved in
a peasant cell of Movimiento Campesino Revolucionario (MCR, spanish for
Revolutionary Peasant Movement) in Los Andes and Quillota (Valparaíso), during the
Unidad Popular's Agrarian Reform in Chile (1970-1973). The reconstruction of this

\footnotetext{
* Este artículo forma parte del proyecto Fondecyt No 11150115 “Articulaciones entre género y memoria social sobre la dictadura cívico-militar chilena desde las prácticas políticas del presente” (2015-2018). Investigadora responsable: María Angélica Cruz. Agradecemos a María Ignacia Banda, Asistente del Proyecto, por el apoyo prestado en este artículo.

** Co-autora, chilena, Doctora en Sociología, Académica del Instituto de Sociología e Investigadora del Centro de Estudios Interdisciplinarios sobre Cultura Política, Memoria y Derechos Humanos de la Universidad de Valparaíso. mariangelica.cruz@uv.cl

${ }^{* * *}$ Co-autor, chileno, Doctorando en Estudios Interdisciplinarios sobre Pensamiento, Cultura y Sociedad, Investigador del Centro de Estudios Interdisciplinarios sobre Cultura Política, Memoria y Derechos Humanos, ambos de la Universidad de Valparaíso, pasante Fondecyt № 11150115 erick.fuentes@ postgrado.uv.cl
} 
trajectory shows how joining MIR is affected by family legacies, the University Reform and an intern's entry in the countryside. In time, the analysis of the way this life story is rebuilt helps us to understand how social memories about the recent past work when they are simultaneously subaltern in three ways; militant, female and local.

Keywords: Social memory, gender, political affiliation, peasant cell, Revolutionary Peasant Movement, Revolutionary Left-wing Movement

Recibido: $19 / 12 / 2016$

Aceptado: 05/07/2017

\section{Introducción}

En el campo de los estudios de memoria sobre las últimas dictaduras en el Cono Sur se ha desarrollado un documentado trabajo sobre la violación de los derechos humanos, las políticas de memoria y, particularmente para el caso chileno, las memorias "emblemáticas". Sin embargo, han quedado invisibilizadas otras narrativas, entre ellas, las que relatan la participación de las mujeres en el quehacer militante de organizaciones políticas de la izquierda revolucionaria, antes y durante la dictadura cívico-militar en Chile. Tal invisibilización nos ha motivado a trabajar con historias de vida de mujeres militantes, asumiendo que ellas no sólo se han desenvuelto en los sectores metropolitanos y en los partidos políticos más tradicionales de la izquierda chilena. Lo hacemos bajo la convicción de que conocer las historias protagonizadas por mujeres que participaron en organizaciones de la izquierda revolucionaria y en los territorios rurales en Chile -en este caso en las localidades de Los Andes y Quillota de la región de Valparaíso- nos permite comprender experiencias que todavía permanecen excluidas de las reconstrucciones históricas realizadas por la razón hegemónica del Chile de la postdictadura; pero también, avanzar en un análisis generizado de las memorias sociales.

En este artículo, a través del relato de vida sobre la trayectoria política de una mujer aún activa, buscamos describir las rememoraciones acerca del vínculo entre la militancia en el Movimiento de Izquierda Revolucionaria (en adelante MIR) y la inserción de estudiantes universitarios/as, particularmente mujeres, en el campo. De esa relación nació el frente de masas denominado Movimiento Campesino Revolucionario (en adelante MCR), que desarrolló un intenso proceso contra la propiedad privada agraria hasta el Golpe de Estado de 1973. A partir de ello exploramos el cruce entre tres tipos de experiencias que desafían los relatos dominantes sobre el pasado reciente en Chile: la experiencia militante de las mujeres (versus la memoria masculina), la subjetividad política revolucionaria (versus la de la izquierda victimizada) y las memorias locales (versus aquellas ancladas en la nación).

Este trabajo es parte de una investigación mayor que analiza cómo se (re)construye el género al hacer memoria del pasado reciente en Chile desde las prácticas políticas del 
presente (Proyecto Fondecyt $\left.N^{\circ} 11150115\right)$ ). Si bien aquí presentamos las rememoraciones sobre una práctica política específica desarrollada durante la Unidad Popular (en adelante UP), los diversos relatos de vida que incluimos en el estudio -también el que aquí analizamos- cubren trayectorias que abarcan la represión política (tortura y prisión), la resistencia durante la dictadura y, a partir del cambio de régimen político, múltiples formas de activismo que combinan posiciones de izquierda, feminismo, memoria y derechos humanos, entre otras. Se trata así de comprender cómo se rememora el pasado en función de compromisos políticos vigentes.

Lo anterior se justifica porque nos interesa el pasado por sí mismo, y nuestras memorias sociales sobre él, pero también porque buscamos poner en diálogo las formas en que tales memorias pueden conectarse con prácticas políticas actuales. Ello porque vivimos un presente en el cual podemos observar -salvando todas las obvias distancias- el resurgimiento de identidades y proyectos políticos que apelan a sentidos de transformación radical del orden vigente, como antes ocurrió con las proyectos de la izquierda revolucionaria, por cierto también vinculados a organizaciones estudiantiles universitarias; colectivos que problematizan lo rural versus lo nacional y, por supuesto, colectivos feministas de distinta índole ${ }^{1}$.

\section{Memoria Social, Género y Subjetividades Políticas}

Como es sabido, "recuperar la memoria" no es solo una consigna que moviliza a las agrupaciones de derechos humanos y los partidos de izquierda que fueron perseguidos durante las dictaduras del Cono Sur. La memoria social se ha venido consolidando como un campo de estudio interdisciplinario en las últimas dos décadas. Allí confluyen tradiciones filosóficas, de la psicología social, sociológicas y, por supuesto, la historia que ha problematizado las relaciones entre lo acontecido y lo rememorado, las paradojas del auge de las conmemoraciones y la memorialización, por nombrar algunas. Así, ya contamos con innumerables investigaciones que cubren experiencias tan disímiles como los totalitarismos europeos del siglo XX, la experiencia sudafricana y las dictaduras del Cono Sur.

\footnotetext{
${ }^{1}$ Para el tema rural, revisar: Beatriz Cid y Alex Latta, "Agro-Ecology and Food Sovereignty Movements in Chile: Sociospatial Practices for Alternative Peasant Futures", Annals of the Association of American Geographers, 105:2, 2015, 397-406. Si bien los movimientos sociales rurales en Latinoamérica se han expandido, Chile es parte de las excepciones, para analizar este tema, ver: Leandro Vergara-Camus, "Rural Social Movements in Latin America: In the Eye of the Storm", Journal of Agrarian Change, 13:4, 2013, 590-606. Para el caso de los jóvenes, revisar: Fuad Hatibovic, Juan Sandoval y Manuel Cárdenas, "Posiciones de sujeto y acción política universitaria: análisis del discurso de estudiantes de universidades de la Región de Valparaíso", Revista Última Década, 20:37, 2012, 111-134. En el tema del feminismo, revisar: Nicole Forstenzer, "Ser feminista en el Chile actual: ambigüedades y dilemas de las reivindicaciones de igualdad de género" UMR 201 Développement et Sociétés, Université Paris I-IEDES, 2013. Igualmente, Claudia Mora y Marcela Ríos, “¿De Política de Representación a Política de Coalición?: Posibilidades de Movilización Feminista en el Chile PostDictadura". Polis, Santiago, 8:24, 2009, 133-145, así como José Manuel Morán Faúndes, "Feminismo, Iglesia Católica y derechos sexuales y reproductivos en el Chile post-dictatorial”, Revista Estudos Feministas, 21:2, 2013, 485-508.
} 
Como hemos argumentado en estudios previos $^{2}$, los énfasis en el Cono Sur han estado puestos en los efectos que la violencia de Estado produjo en las víctimas directas e indirectas, en su procesamiento social y político y en las disputas sociales entre memorias. Para el caso chileno, se han investigado principalmente las formas de enfrentar el pasado en el ámbito político-institucional, a nivel de la sociedad y lo ocurrido con las víctimas más directas de la represión política. Junto con eso, y sin pretender agotar el campo, sabemos que se han estudiado las disputas colectivas y el asentamiento de memorias "emblemáticas" de la dictadura ${ }^{3}$, los "vehículos de memoria" tales como la enseñanza de la historia, los lugares de memoria o las conmemoraciones, más una abundante producción de la historiografía sobre el pasado reciente.

Asumiendo que la memoria social es polifónica (se habla también de memoria colectiva, memoria histórica, entre otras), de acuerdo a Elizabeth $\mathrm{Jelin}^{5}$, la entendemos como un concepto que permite interrogarnos sobre cómo van tomando forma los sentidos acerca del pasado en función de los desafíos del presente. Se trata de una práctica social que supone siempre no sólo recuerdos sino también silencios y olvidos ${ }^{6}$. Luego, al ser un proceso socialmente construido, las memorias son siempre en plural y están en permanente disputa entre distintos actores que buscan legitimar ciertas narrativas sobre el pasado y cómo hay que recordarlo: luchas entre memorias oficiales ${ }^{7}$, emblemáticas ${ }^{8}$ y subalternas ${ }^{9}$, entre otras. A su vez, la memoria social está fuertemente vinculada a la producción de identidades y los sentidos de pertenencia a una comunidad ${ }^{10}$.

A partir de ello, actualmente nos interesa problematizar dos ejes. Primero, visibilizar la experiencia militante. Tal como lo ha problematizado Jelin ${ }^{11}$ para el Cono Sur, tras años de negación del terrorismo de Estado, fue muy importante dar cuenta de la represión política bajo el paradigma de los derechos humanos. Ese paradigma fue necesario y/o estratégico de sostener una vez terminadas las dictaduras, pero como todo marco supone recortes y tiene consecuencias. La más clara es que el éxito de las memorias dominantes emprendidas, tanto desde las políticas públicas como desde el movimiento de

\footnotetext{
${ }^{2}$ Marcela Cornejo, María José Reyes, María Angélica Cruz, Nicolás Villarroel, Anastassia Vivanco, Enzo Cáceres y Carolina Rocha, "Historias de la Dictadura Militar Chilena desde Voces Generacionales", Revista Psykhe, 22:2, 2013, 4965 .

${ }^{3}$ Steve Stern, "De la memoria suelta a la memoria emblemática: Hacia el recordar y el olvidar como proceso histórico (Chile, 1973-1998)", en Elizabeth Jelin (comp.), Las conmemoraciones: Las disputas en las fechas "in-felices", Buenos Aires, Siglo XXI Editores, 2002, 11-33.

${ }^{4}$ Elizabeth Jelin, Los trabajos de la memoria, Buenos Aires, Siglo XXI Editores, 2002.

${ }^{5}$ Idem.

${ }^{6}$ Para profundizar sobre la memoria como práctica social, revisar: Félix Vázquez, La memoria como acción social. Relaciones, significados e imaginario, Barcelona, Paidós, 2001; para el tema de los silencios y olvidos en las memorias colectivas, revisar: Maurice Halbwachs, La memoria colectiva, Zaragoza, Prensas Universitarias de Zaragoza, 1968; Alessandro Portelli, La orden ya fue ejecutada. Roma, las Fosas Ardeatinas, la memoria, Buenos Aires, Fondo de Cultura Económica, 2004; Dave Middleton \& Derek Edwards, Collective remembering, London, Sage Publications, 1990.

${ }^{7}$ Jelin, 2002, op. cit.

${ }^{8}$ Stern, op. cit.

${ }^{9}$ Enzo Traverso, El pasado, instrucciones de uso. Historia, memoria, política, Madrid, Marcial Pon, 2007.

${ }^{10}$ Michael Pollak, Memoria, olvido, silencio, Buenos Aires, Al Margen, 2006.

${ }^{11}$ Elizabeth Jelin, "La conflictiva y nunca acabada mirada sobre el pasado", Marina Franco y Florencia Levín (comps.), Historia reciente. Perspectivas y desafíos para un campo en construcción, Buenos Aires, Paidós, 2007.
} 
derechos humanos, ha supuesto invisibilizar las prácticas de resistencia a la dictadura, los proyectos de transformación social que motivaron la represión política, y en general el sentido de actor- no sólo de "víctima inocente"- que tiene todo/a sujeto político. Lo anterior ha empezado a ser problematizado hace algunos años en el país vecino, por ejemplo por $\mathrm{Crenzel}^{12}$, y más recientemente también en Chile. Por poner solo un ejemplo que hemos presentado en otro lugar, la forma en que muchos jóvenes recepcionan e interpretan ciertos memoriales sobre la represión política muestra claramente las consecuencias que ha tenido, en términos de socialización política, una memoria dominante que sólo fija a los militantes y luchadores sociales como "víctimas apolíticas"13. De ahí que aquí nos importe focalizarnos en las memorias de la militancia, precisamente aquellas que la persecución política demonizó y buscó exterminar.

El segundo eje que nos interesa es la articulación entre memoria y género. A partir de la investigación en curso, al revisar la literatura sobre el Cono Sur, y particularmente la referida al caso chileno, identificamos tres grandes líneas, no necesariamente excluyentes. En primer lugar, contamos con diversos trabajos sobre las consecuencias que las dictaduras militares tuvieron para las mujeres, particularmente la represión política. En el segundo, se pone énfasis en las diversas prácticas de militancia, resistencia y activismo femenino. Una tercera línea, que a veces busca superar a las dos anteriores, reclama que más que estudiar lo que "ocurrió con las mujeres" hay que articular memoria y género evitando caer en los riesgos de un cierto "esencialismo" presente en los estudios sobre las mujeres y sus formas de hacer memoria. Para lo que aquí nos convoca importa considerar especialmente la segundo y tercera línea.

Con relación a la segunda, encontramos investigaciones que buscan reivindicar las experiencias de las mujeres frente a su subestimación u olvido, particularmente su activismo. Desde aquí se trata de "rescatar" el "rol" jugado por las mujeres en la lucha contra las dictaduras, reivindicando su capacidad de agencia ${ }^{14}$. Entre otras prácticas, hay que considerar que muchas mujeres participaron en la militancia armada ${ }^{15}$, siendo actoras plenamente involucradas en frentes que luego han sido recordados como netamente masculinos. Además, se recalcan las dificultades que ellas habrían enfrentado en el trato con sus pares y las tensiones provocadas por la imagen de una mujer masculinizada, con

\footnotetext{
${ }^{12}$ Emilio Crenzel, La historia política del Nunca Más. La memoria de las desapariciones en la Argentina, Buenos Aires, Siglo XXI Editores, 2008.

${ }^{13}$ María José Reyes, María Angélica Cruz y Félix Aguirre, "Los lugares de memoria y las nuevas generaciones: Algunos efectos políticos de la transmisión de memorias del pasado reciente de Chile”, Revista Española de Ciencia Política, 41, 2016, 93-114.

${ }^{14}$ Margarita Iglesias, "Dictaduras personales. Dictaduras colectivas: mujeres militantes y movimientos sociales. Chile 1973-1999”, Tania Medalla, Alondra Peirano, Olga Ruiz y Regine Walch, (eds.), Recordar para pensar. Memoria para la Democracia. La elaboración del pasado reciente en el Cono Sur de América Latina, Santiago de Chile, Ediciones Heinrich Böll Cono Sur, 2010, 221-229; Kelley Boldt and Timothy White, "Chilean Women and Democratization: Entering Politics through Resistance as Arpilleristas”, Asian Journal of Latin American Studies 24:2, 2011, 27-44.

15 Tamara Vidaurrázaga, “¿El hombre nuevo?: moral revolucionaria guevarista y militancia femenina. El caso del MIR”, Revista Nomadías, 15, 2012, 69-89.
} 
uniforme y armas, y un cuerpo que rechaza todo rasgo "femenino" 16.

En la tercera línea, los estudios promueven análisis que incluyan la incorporación de un enfoque de género para entender cómo operan las memorias sociales, preguntándose por la presencia de categorías, simbologías y discursos marcados por el género en los trabajos de la memoria ${ }^{17}$. Desde allí, por ejemplo, se intenta dar cuenta de los prismas tradicionales de género con que se analiza la labor de las agrupaciones de derechos humanos desde un enfoque "maternalista" y "familista", en el cual las mujeres desaparecen como sujetos y se trasmiten aquellos sentidos asociados a la valentía y sacrificio materno ${ }^{18}$. Asimismo, se interpreta el conjunto de las memorias en una distinción tradicional entre el Estado (masculino) y las víctimas (femeninas) ${ }^{19}$. En una línea similar se ubican las reflexiones que reclaman que más que agregar la variable género a los estudios de memoria hay que buscar la memorización del género y la generización de la memoria ${ }^{20}$.

Para el caso que nos ocupa importa tener en cuenta particularmente los análisis de Hiner ${ }^{21}$ que invitan a pensar los efectos de verdad que producen las memorias oficiales tales como los informes Rettig y Valech- utilizando los constructos analíticos del género y del feminismo. Tales análisis permiten examinar la construcción de víctima-victimario en la memoria oficial; un dispositivo de normalización y legitimación del proceso de transición democrática que se presenta como lo inmediatamente opuesto a lo autoritario y represivo de la dictadura. Desde allí salen a la luz aspectos no observables de la memoria a simple vista, como los discursos en que se intenta presentar a las víctimas de la represión como personajes altruistas antes que políticos, y ante todo "inocentes". Así, la "víctima" no es reconstruida como sujeto en pleno ejercicio de su politicidad. Retomando esto, creemos que, al ampliar los límites temporales de las memorias del pasado a lo ocurrido antes del Golpe de Estado, se posibilita incluir la experiencia militante de las mujeres más allá de las memorias del dolor.

En tal sentido, y considerando que el relato que analizaremos se refiere a la participación militante en los procesos de Reforma Agraria que se llevaron a cabo durante la Unidad Popular en el Valle del Aconcagua, resulta muy iluminador el trabajo de Heidi Tinsman sobre dicho proceso desde una perspectiva de género. Su trabajo es fundamental para entender cómo la Reforma Agraria mejoró significativamente las condiciones de vida de hombres y mujeres en el campo, pero también que para el caso de las mujeres operaron "jerarquías de género que hicieron que esa superación fuese inferior y subordinada a la de

\footnotetext{
${ }^{16}$ Elizabeth Jelin, "Subjetividad y esfera pública: el género y los sentidos de familia en las memorias de la represión”, Revista Política y Sociedad, 48:3, 2011, 55-569.

${ }^{17}$ Jelin, 2011, op. cit.; Hillary Hiner, "Violencias soterradas, voces silenciadas. Discurso, violencia política y género en los Informes Rettig y Valech", Latin American Research Review, 44:3, 2009, 50-74.

${ }^{18}$ Hillary Hiner, "They Dance Alone': Gender in the Chilean Transition to Democracy”, Revista Anamesa, 3:1, 2005, 322.

${ }^{19}$ Jelin, 2011, op. cit.

${ }^{20}$ Leyla Troncoso e Isabel Piper, "Género y Memoria: articulaciones críticas y feministas", Athenea Digital, 15:1, 2015, 66.

${ }^{21}$ Hiner, 2005, op.cit.
} 
los hombres" 22 . Este agudo análisis se relaciona con lo planteado por Mack, Matta y Valdés, cuando señalan que las identidades de género en el campo se sostienen sobre la comprensión de que "la sociedad en su conjunto tiene una particular forma de concebir el trabajo" lo cuál afecta a las mujeres, "porque las niega como personas que contribuyen a generar la fuerza de trabajo, a alimentarla, en fin, a reproducirla" ${ }^{23}$. Así es posible dar cuenta de cómo el trabajo agrícola fue por mucho tiempo comprendido en clave masculina, invisibilizando la participación de la mujer para relegarla a su rol en la familia y cómo, según Valdés y Rebolledo, la Reforma Agraria comienza a agrietar dicha estructura, "con la emergencia del sindicalismo y la cercanía de los campesinos con las instituciones del Estado" 24 .

A su vez, importa considerar que al cruzar memoria y género observamos ciertas disputas por "el papel de las mujeres" que fueron sostenidas tanto por la izquierda como por la derecha, en las cuales concurren una serie de mandatos sobre el deber ser femenino asociados a la maternidad (revolucionaria o no) y el apoyo al "verdadero" sujeto revolucionario, un hombre igualmente teatralizado en concordancia con el proyecto político $^{25}$ y de una masculinidad mesiánica fiel a las relaciones de género tradicionales ${ }^{26}$.

Con ello nos acercamos a otro lente teórico que también orienta el análisis que aquí presentamos: la subjetividad del proyecto político revolucionario. Al respecto hay que considerar que las organizaciones de la nueva izquierda nacidas en Latinoamérica luego de la Revolución Cubana, agregaron a su teoría marxista-leninista el guevarismo, basado en la idea de que la revolución posibilitaría no solo cambios sociales sino también el nacimiento de un "hombre nuevo" 27 asociado a una moral revolucionaria que era sostenida por mandatos militantes ${ }^{28}$. Según el pensamiento guevarista, no había que esperar a que los cambios sociales y económicos cambiaran por sí solos a los individuos, sino que ellos debían poner su empeño en ser coherentes con el proceso de transformación. Así, promoverían un mayor cambio en el sistema productivo toda vez que trabajarían por el sentido de responsabilidad revolucionaria y no por el dinero y el goce individual que éste les daría ${ }^{29}$. Tanto el 'Che' Guevara, como Miguel Enríquez en Chile, dan muestra de las normas revolucionarias que regulaban la vida personal y social:

la ejemplaridad es una avanzada hacia el comunismo; ella registra los sucesivos parámetros que permiten medir al hombre nuevo que 'que va naciendo', 'que estamos

\footnotetext{
${ }^{22}$ Heidi Tinsman, La Tierra para el que la trabaja. Género, sexualidad y movimientos campesinos en la Reforma Agraria chilena, Santiago, LOM Ediciones, 2009, 11.

${ }^{23}$ Macarena Mack, Paulina Matta y Ximena Valdés, Los trabajos de las mujeres entre el campo y la ciudad 1920-1982, Santiago, Centro de Estudios de la Mujer, 1986, 5-7.

${ }^{24}$ Ximena Valdés y Loreto Rebolledo, "Géneros, generaciones y lugares: cambios en el medio rural de Chile Central", Polis, Santiago, 14:42, 491, 2015.

${ }^{25}$ Graciela Sapriza, "Memorias de mujeres en el relato de la dictadura (Uruguay, 1973-1985). Violencia/cárcel/ exilio", Revista Telemática di Studi Sulla Memoria Femminile, 11, 2009, 64-80;

${ }^{26}$ Hiner, 2009, op. cit.

${ }^{27}$ Vidaurrázaga, 2012, op. cit.

28 Olga Ruiz, "Mandatos militantes, vida cotidiana y subjetividad revolucionaria en el Movimiento de Izquierda Revolucionaria de Chile (1965-1975)", Revista Austral de Ciencias Sociales, 28, 2015, 163-182.

${ }^{29}$ Fernando Martínez, Pensar al Che, citado por Vidaurrázaga, 2012, op. cit., 71.
} 
creando`, no a un mítico hombre nuevo que encontraremos al final de los tiempos. Trata de cambios en la totalidad del individuo, mediante los cuales sus acciones, su intelección y sus afectos y sentimientos se entregan cada vez más a la colectividad y menos al interés individual, y el deber se va tornando paulatinamente en satisfacción y en placer $^{30}$

el militante revolucionario debe observar las mismas normas de comportamiento en la actividad política como en la vida privada. En todo momento debe presentar el ejemplo vivo de una nueva moral, prefigurando el futuro ser humano integral de la sociedad socialista $^{31}$

Para las organizaciones guevaristas latinoamericanas -donde se inscribió el MIR- la vanguardia debía dar ejemplo de esa transformación mediante la lucha política y armada orientada hacia la revolución, bajo el convencimiento de que el partido era la expresión de la organización del pueblo. Allí entonces se comprende la subjetividad revolucionaria como ejemplar, sacrificial y heroica. Sin embargo, si bien las mujeres participaron activamente en este tipo de partidos, esa subjetividad revolucionaria que aparece como neutra se pensaba en una lógica más bien masculina, patriarcal y hegemónica ${ }^{32}$.

De acuerdo a ello, se hace necesario profundizar sobre esta relación entre subjetividad revolucionaria y proyecto político en los estudios de memoria del pasado reciente de Chile, para comprender como se han invisibilizado las trayectorias políticas de mujeres militantes de organizaciones sociales y políticas de la izquierda revolucionaria, desde un campo de acción subalterno en términos de identidades políticas, de género y territorio.

Lo anterior implica también un cambio de foco en los estudios de memoria: se vuelve relevante el análisis de los procesos de construcción de memorias en comunidades locales, ubicadas territorial, simbólica y políticamente lejos de las ciudades capitales y los poderes centrales ${ }^{33}$. En este caso, la experiencia transmitida por el relato de vida bajo el enfoque biográfico ${ }^{34}$ queda situada no sólo desde la militancia revolucionaria y el género, sino también desde la territorialidad rural, en este caso, de la región de Valparaíso.

En cuanto a la historiografía sobre el MIR para el periodo 1965-1973, es posible sostener que ésta se concentra principalmente en los aspectos y problemáticas referidas a su etapa fundacional y el impacto que tiene el surgimiento del MIR en la trayectoria del movimiento popular y la izquierda chilena ${ }^{35}$.

\footnotetext{
${ }^{30}$ Ernesto Guevara, El Pensamiento Revolucionario del "Che”, citado por Vidaurrázaga, 2012, op. cit. 72.

${ }^{31}$ Miguel Enríquez, Con vista a la esperanza, citado por Vidaurrázaga, 2012, op. cit. 81.

32 Alejandra Oberti, Las Revolucionarias. Militancia, vida cotidiana y afectividad en los setenta, Buenos Aires, Edhasa, 2014; Vidaurrázaga, 2012, op. cit.; Ruiz, 2015, op. cit.; Hiner, 2015, op. cit.

${ }^{33}$ Ponciano del Pino y Elizabeth Jelin, Luchas locales, comunidades e identidades, Buenos Aires, Siglo XXI, 2003.

${ }^{34}$ Daniel Bertaux, Los relatos de vida. Perspectiva etno-sociológico, Barcelona, Bellaterra, 2005.

${ }^{35}$ Este párrafo y los siguientes, más las nutridas notas al pie que indican un amplio listado de referencias bibliográficas, están en deuda con los generosos aportes de Claudio Pérez, historiador del Instituto de Historia de la Universidad de Valparaíso y especialista en movimientos de la izquierda armada en América Latina. Agradecemos a Claudio las
} 
De esta manera, los debates sobre el origen del MIR y la irrupción de la lucha armada en Chile; las tensiones partidarias que gestaron la salida de trotskistas y anarquistas, el peso de los sectores Castro-guevaristas en su interior y posterior despliegue orgánico en la conducción partidaria ${ }^{36}$; el estudio de sus grandes cuadros dirigentes, las formulaciones políticas y estratégicas del MIR y el desarrollo del proyecto revolucionario ${ }^{37}$, así como el desarrollo de los aspectos identitarios y culturales de su militancia y su relación con las distintas vertientes y dinámicas del movimiento popular chileno (pobladores, campesinos, estudiantil, trabajadores) han acaparado gran parte de los intereses historiográficos en la última década ${ }^{38}$. Quedan pendientes nuevos estudios que den cuenta de los procesos de politización que experimentaron cientos de trabajadoras y trabajadores, del campo y la

conversaciones sostenidas sobre la historia del MIR, así como sus contribuciones sobre la literatura más especializada en este tema.

${ }^{36}$ Marco Álvarez Vergara, La constituyente revolucionaria. Historia de la fundación del MIR chileno, Santiago, LOM Ediciones, 2015; Mario Amorós, La memoria rebelde, Concepción, Escaparate Ediciones, 2008; Enérico García Concha, Todos los días de la vida. Recuerdos de un militante del MIR chileno, Santiago, Cuarto Propio Ediciones, 2010; Igor Goicovic, Movimiento de Izquierda Revolucionaria, Concepción, Escaparate Ediciones, 2012; Sergio Salinas, El tresletras. La historia del MIR, RIL Editores, 2013; Sandoval Ambiado, Carlos, MIR. Una historia, Sociedad Editorial Trabajadores, Santiago de Chile, Santiago, 1990; Carlos Sandoval Ambiado, Movimiento de Izquierda Revolucionaria 1970-1973. Coyunturas, documentos y vivencias, Concepción, Escaparate Ediciones, 2004; Hernán Vidal, Presencia del Movimiento de Izquierda Revolucionaria (14 claves existenciales), Santiago, Mosquito, 1999; Hernán Vidal, El Movimiento de Izquierda Revolucionaria (MIR) de Chile en la justicia transicional, Santiago, Alternativas, 2014; Luis Vitale, Contribución a la historia del MIR (1965-1970), Santiago, Ediciones Instituto de Investigación de Movimientos Sociales Pedro Vuskovic, 1999; Igor Goicovic, "El contexto en el que surge el MIR", Revista del CEME, 6, Estocolmo, 2000; Igor Goicovic, "El Movimiento de Izquierda Revolucionaria (MIR) y la irrupción de la lucha armada en Chile, 1965-1990", en Pozzi, Pablo y Pérez, Claudio (Edit.), Historia oral e historia política. Izquierda y lucha armada en América Latina 1960-1990, Santiago, LOM Ediciones - UAHC, 2012; Iñaki Moulian, Contextualización, origen y evolución del Movimiento de Izquierda Revolucionaria (MIR) en Chile 1959-1970, Tesis de Licenciatura, Valdivia, Universidad Austral de Chile, 2001; Pedro Valdés Navarro, Elementos teóricos en la formación y desarrollo del MIR durante el período 1965-1970, Valparaíso, Tesis de Licenciatura, Universidad de Valparaíso, 2006. Considerando que todas estas referencias no son textos que hayamos trabajado en este trabajo, y a fin de no extender más el texto, no la hemos incluimos en la bibliografía que aparece al final.

37 Martín Hernández Vásquez, El pensamiento revolucionario de Bautista van Schouwen 1943-1973, Concepción, Escaparate, 2004; Igor Goicovic, "Violencia y poder en la estrategia del Movimiento de Izquierda Revolucionaria, 19671986”, Cuadernos Sociológicos, 3, Santiago, 2004; Pedro Naranjo et. Al (Comp.), Miguel Enríquez: El proyecto revolucionario en Chile, Santiago, LOM Ediciones, 2004; Inés Nercesian, La política en armas y las armas de la política: Brasil, Chile y Uruguay 1950-1970, Buenos Aires, CLACSO, 2013; Cecilia Radrigán y Miriam Ortega (Comp.), Miguel Enríquez: Con vista a la esperanza, Santiago, Escaparate Ediciones, 1998; Martín Hernández, "Carácter y programa de la revolución proletaria en la concepción de Miguel Enríquez", en Pedro Naranjo (Coord.), Miguel Enríquez. Páginas de historia y lucha, Estocolmo, Centro de Estudios Miguel Enríquez (CEME), 1999; Ivette Lozoya López, "Pensar la revolución: Pensamiento latinoamericano e intelectuales en el MIR chileno, 1965-1973. Propuesta teórica y metodológica para su estudio desde la historia intelectual y la historia de la violencia", Revista de Humanidades, 27, Santiago, 2013; Pedro Naranjo, "Semblanza biográfica y política de Miguel Enríquez”, Pedro Naranjo (Coord.), Miguel Enríquez. Páginas de historia y lucha, Estocolmo, Centro de Estudios Miguel Enríquez (CEME), 1999

${ }^{38}$ José Manuel Bravo Aguilera, De Carranco a Carrán. Las tomas que cambiaron la historia, Santiago, LOM Ediciones, 2012; Hugo Cancino Troncoso, Chile: La problemática del poder popular en el proceso de la Vía Chilena al Socialismo 1970-1973, Copenhague, Aarhus University Press, 1988; Boris Cofré Schmeisser, Campamento Nueva La Habana. El MIR y el movimiento de pobladores 1970-1973, Concepción, Escaparate Ediciones, 2007; Sebastián Leiva Flores, Revolución socialista y poder popular. Los casos del MIR y del PRT-ERP 1970-1976, Concepción, Escaparate Ediciones, 2010; Matías Ortiz Figueroa, Cada día es continuar. Política e identidad en el MIR 1965-1970, Concepción, Escaparate Ediciones, 2014; Guillermo Rodríguez, De la brigada secundaria al Cordón Cerrillos, Santiago, Universidad Bolivariana, 2007. Considerando que todas estas referencias no son textos que hayamos trabajado en este trabajo, y a fin de no extender más el artículo, no la hemos incluimos en la bibliografía que aparece al final. 
ciudad, jóvenes, intelectuales, estudiantes y pobladores, que desde distintas experiencias de vida, dieron sentido a su práctica social y se enrolaron en las filas del $\mathrm{MIR}^{39}$.

Sobre esto último, este trabajo pretende aportar precisamente a la comprensión de dicho proceso de politización, con especial énfasis en su dimensión de género. En tal sentido, aunque nuestro énfasis está puesto en las militancias femeninas, podemos destacar especialmente el trabajo de Igor Goicovic y de Francisco Aspee Bou referidos a jóvenes varones.

\section{Nota Metodológica}

El diseño metodológico del estudio mayor (Fondecyt $\mathrm{N}^{\mathrm{o}}$ 11150115), en el que se insertan los resultados que aquí exponemos, se basa en la lógica cualitativa que trabaja con diversos casos y escenarios seleccionados de acuerdo a los criterios teóricos que orientan la investigación ${ }^{40}$. En este artículo presentamos el análisis de uno de los relatos de vida correspondiente al de una mujer militante del MIR con una trayectoria política, desde el año 1970 a la fecha, en la región de Valparaíso.

El tipo de estudio es de carácter exploratorio, en tanto busca levantar información sobre un problema muy poco investigado en Chile a la fecha, lo que permitiría avanzar hacia una comprensión mayor de un fenómeno complejo como lo es la articulación del género en la memoria y la subjetividad revolucionaria en un proyecto político expresado en la región de Valparaíso como lo es el MCR, frente intermedio del MIR. A su vez, se trata de un diseño cualitativo que busca comprender "la emergencia del hablar o el significar social" como rostro observable de la sociedad. De acuerdo a lo anterior, este tipo de investigación se mueve en el orden de los significados y sus reglas de significación, tratando de alcanzar la estructura de observación del otro, su "espacio subjetivocomunitario" o "red intersubjetiva" 41 .

La técnica de producción de datos ha sido el "relato de vida", tal como lo propone Bertaux desde una perspectiva etnosociológica ${ }^{42}$. De acuerdo a lo anterior, se realizó un relato de vida singular basado en la citada trayectoria política, entendiéndolo como portador de la historia social que la sustenta y la construye para acceder a lo social desde lo biográfico.

\footnotetext{
${ }^{39} \mathrm{Al}$ respecto, podemos destacar el trabajo de Igor Goicovic, "De la dura infancia, de la ardiente vida, de la esperanza... Un testimonio popular para la reconstrucción de nuestra historia reciente", Última Década, 6, Viña del Mar, 1997 y de Francisco José Aspee Bou, Resistencia, voluntad y revolución en La Serena. Historias de vidas de actores sociales miristas en la ciudad de La Serena 1970 y 1975, La Serena, Tesis de Licenciatura, Universidad Pedro de Valdivia, 2012.

${ }^{40}$ El diseño metodológico del proyecto Fondecyt $N^{\circ} 11150115$ arranca con los relatos de vida de mujeres militantes para analizar diversas trayectorias políticas, pero luego se suman otras técnicas tales como entrevistas a informantes claves, entrevistas en profundidad a cargos de representación y participantes de colectivos y movimientos sociales, observación participante de marchas y protestas, seguimiento de campañas electorales y análisis de foros virtuales para cubrir diversas prácticas políticas -convencionales y no convencionales- del presente.

${ }^{41}$ Manuel Canales, Metodologías de investigación social, LOM Ediciones, 2006.

${ }^{42}$ Bertaux, op.cit.
} 
El relato fue elaborado a partir de dos encuentros, en base a una invitación inicial para conversar acerca de su historia de participación política antes, durante y después de la dictadura. En el primer encuentro la conversación se inició tras la consigna "Cuéntame tú trayectoria política tal como tú la quieras contar”. Esto permitió que la narradora estructurara el curso y trama de su narración. En el segundo encuentro se completó el relato, se profundizó en los aspectos menos claros del primero, se comentó la experiencia del primer encuentro y se invitó a reflexionar más directamente sobre el presente. Entre el primer y segundo encuentro se le entregó a la narradora una copia de la transcripción del primer encuentro, tanto para contar con su aprobación sobre lo transcrito, como para activar nuevos recuerdos y poder conversar sobre la experiencia de haber narrado lo que contó en la primera sesión. El primer encuentro fue grabado en video y sonido ya que se espera utilizar parte del material para hacer un micro-documental. El segundo fue registrado solo en grabadora de sonido ${ }^{43}$. Ambos encuentros se realizaron en el primer semestre del año 2016.

El análisis de los datos corresponde a lo que se conoce como análisis cualitativo teóricamente guiado ${ }^{44}$ en base a la aplicación de los diversos conceptos y dimensiones antes presentadas sobre la memoria social, el género y las prácticas políticas. No obstante, en términos operativos, ese análisis se mezcla con un análisis de contenido y del discurso. El análisis de contenido lo entendemos como un conjunto de métodos que buscan identificar códigos y categorías de análisis previamente definidas y/o identificando aquellas que emergen del material a sistematizar ${ }^{45}$ y la aplicación del enfoque teórico; mientras que el análisis de discurso busca indagar en los elementos más densos e ideológicos del habla y de los textos orientados especialmente por un análisis sociológico del discurso ${ }^{46}$.

Re-construyendo los inicios de la militancia: entre la tradición política familiar, la subjetividad política revolucionaria, la reforma universitaria y el descubrimiento del campo.

María actualmente es trabajadora social, vive en Valparaíso y bordea los sesenta años. Ante la invitación a narrar su trayectoria política, se retrotrae a sus tiempos de juventud, pero comienza su relato de la siguiente manera:

Bueno la verdad que... hablar de trayectoria política es como... es bien amplio, pero yo creo que tiene mucho que ver con los contextos y la vida cotidiana donde uno ha nacido y donde uno ha hecho su vida de infancia y de adolescencia. Y bueno, yo también he pensado muchas veces ¿de dónde a mí me vino esta visión del mundo? (...)

\footnotetext{
${ }^{43}$ Ambos encuentros fueron transcritos literalmente. Siguiendo el protocolo ético de la investigación, contamos con un consentimiento informado de la narradora y un pacto de resguardo del anonimato. Hay que aclarar que el anonimato no fue algo que preocupara a la narradora, pero sí es una de las exigencias del Comité de Bioética que aprobó el proyecto de investigación. En razón de ello aquí utilizamos un nombre ficticio en todas las citas.

44 Amanda Coffey y Paul Atkinson, Encontrar el sentido a los datos cualitativos, Medellín, Editorial Universidad de Antioquía, 1996.

${ }^{45}$ Idem.

${ }^{46}$ Luís Enrique Alonso, La mirada cualitativa en sociología, Barcelona, Fundamentos, 1998.
} 
que yo creo que viene por parte de mis abuelos (...) los abuelos vienen del norte (..) trabajaron en la salitrera y siempre nos contaban la historia cuando éramos muy pequeños de cómo habían logrado escapar de toda la represión de González Videla (...) y nosotros además la escuchábamos en las reuniones familiares (...) como que estaba en el contexto familiar el ser de izquierda y el tener una mirada de deseos de igualdad y de derechos (...) también a uno la va marcando y dentro de eso, como te comentaba era como muy normal escuchar estas historias de luchas políticas y en ese tiempo, también de clandestinidad porque los abuelos tuvieron que arrancar (...) había un entorno político que te, que te hacía tener una mirada frente a la vida y una posición también, o sea, mi familia es toda de clase trabajadora y bueno, yo creo de ahí empezaron como mis primeras nociones

Tal como señala Oberti, ${ }^{47}$ para el caso de las militancias femeninas en organizaciones de la izquierda revolucionaria en Argentina, los referentes familiares son importantes en la decisión de ingresar a la política, contribuyendo a elaborar continuidades o rupturas con la tradición familiar. En el caso de María, su elaboración es de continuidad con la experiencia de su familia, obrera y comunista, perseguida por luchar por mejores condiciones de vida en el Norte del país.

No obstante, lo que nos interesa es resaltar que en esta forma de construir el relato observamos un modo en que la memoria trabaja de manera generizada. Como hemos problematizado en otro lugar $(\mathrm{Cruz}, 2016)^{48}$, los varones suelen arrancar el relato de su trayectoria política vinculándolo a su ingreso al partido en el contexto de la universidad; en cambio, todas las mujeres que participaron del estudio parten narrando sus trayectorias desde sus familias de origen, recordando sus infancias y cómo las marcaron las conversaciones familiares o la forma de entender el país y vivir la política que tenían sus padres. Asimismo, cuando se establecen herencias o rupturas con las figuras familiares se trata siempre de personajes masculinos. Esto puede ser coherente con la distribución tradicional de roles de género de la época, pero también con una memoria generizada, ya que en sus rememoraciones solo los padres, abuelos o hermanos mayores son recordados como sujetos políticos, no así las mujeres.

Con todo, en el caso de María la madre aparece, pero en clave de ubicación en las posiciones de clase. Así, la ascendencia paterna (obrera) y materna (campesina), sirven a la narradora para auto ubicarse en un contexto donde hereda la posición antagónica del abuelo materno:

y por parte de mi madre, mis abuelos eh... son de tradición campesina de los campesinos más... más duros en términos de vida, podríamos decir los más explotados. Entonces el siempre, el llego de parte de toda la pobreza que viene del sur de los campesinos, llego a trabajar acá a Viña y se puso a trabajar en la fábrica, en la

\footnotetext{
${ }^{47}$ Oberti, 2014, op. cit.

${ }^{48}$ María Angélica Cruz, Articulaciones entre género y memoria social: los inicios de las trayectorias políticas femeninas antes del Golpe de Estado en Valparaíso y la pertinencia del "punto de vista" de las mujeres, Ponencia en II Seminario Internacional "Nuevos desafíos a los estudios sobre memoria en el contexto latinoamericano actual" organizado por la Red Interdisciplinaria de Estudios sobre Memoria Social (RIEMS), Mar del Plata, 26 y 27 de octubre, 2016.
} 
CRAV, fábrica de azúcar que había en ese tiempo. Entonces él siempre tenía, algo así como, no era tan político como mis otros abuelos, pero el tenia así como un instinto de clase y él hablaba pestes de los dueños de la fábrica y en ese tiempo hablaban del capataz, que era como el tipo que los controlaba y que hacia la disciplina de que llegaran a la hora, de que trabajasen, entonces él siempre hablaba muy mal de esa, de la gente que... que el veía que como que era como sus enemigos

Sin embargo, esa no fue la única influencia determinante en la subjetividad de María, puesto que su identidad personal se reconstruye en el relato desde una posición de sujeto protagónico que no se ajusta al mandato tradicional del género. Ella se recuerda así misma como una niña interesada en la cultura, la política y no en las actividades y juegos típicos de niñas. Este tipo de relato sobre la infancia de María también coincide con los de otras mujeres militantes incluidas en el estudio. En todos ellos las mujeres se recuerdan a sí mismas como diferentes a sus pares en esta forma de encarnar la norma de género.

Ahora durante un tiempo, yo creo que por ahí, por los 60's él [abuelo materno] tuvo que haber tenido contacto con gente, con alguien que... eh... le habló de la... de la Revolución China, porque empezó a llegar a la casa con una cantidad de libros muy bien diagramados con un papel muy bonito y que mostraban toda la revolución cultural de los chinos, la Gran Marcha.... entonces ahí yo empecé a conocer, tenía como 8, 10 años, empecé a conocer toda la historia de lo que significaba la Revolución China

Esto es relevante para comprender a parte de una generación de mujeres altamente preocupadas por el acontecer de la realidad internacional y por discutir e involucrarse en la vida política del país. Algo que, desde una perspectiva de género, importa no sólo porque muestra que eran mujeres jóvenes que a finales de los años 60' vivían rápidas transformaciones en el orden de género, desafiando el confinamiento al espacio privado y doméstico, sino que también porque ellas al hacer memoria sobre los inicios de sus trayectorias políticas destacan esas prácticas como algo relevante: eran jóvenes informadas, interesadas en la política contingente y a quienes "les daban vuelta" en la cabeza ideas diferentes a las expectativas de género tradicionales.

leía las noticias respecto de la Revolución Cubana, a Camilo Cienfuegos, a Fidel, al asalto de Moncada que tuvo harta, harta propaganda acá en Chile en esos diarios (...) y... también al Che (...) estaba también todo lo que eran las luchas en América Latina, sindicales fundamentalmente, que esa salían en los diarios eh... pero me daban vuelta por ejemplo, hay una idea que me quedó dando vuelta durante mucho tiempo que fue el nacimiento, surgimiento del MIR en Concepción, también lo vi a través de los diarios. Y lo discutí, era impresionante en ese tiempo, yo discutí los asaltos que hacia el MIR en ese momento

Con esta cita pasamos más directamente a la memoria militante. Para enmarcarla, habría que recordar que desde su fundación en el año 1965, el Movimiento de Izquierda Revolucionaria $(\mathrm{MIR})^{49}$ se reconoce como parte y heredero de la trayectoria de luchas de

\footnotetext{
${ }^{49}$ Agradecemos las recomendaciones hechas sobre este tema por el historiador Claudio Pérez, académico del Instituto de Historia de la Universidad de Valparaíso.
} 
los trabajadores y del campo popular, buscando llevar adelante un programa revolucionario para los trabajadores del país, como resultado del desarrollo del movimiento popular y de los crecientes niveles de empoderamiento alcanzados durante el siglo XX desde la proletarización forzada en los albores de la modernización capitalista del siglo XIX ${ }^{50}$. A ese marco histórico y social nacional, se añaden los influjos de la guerra de Vietnam y la Revolución Cubana, como una oleada de hechos transformadores que calaron hondo en las expectativas político-sociales del momento. El carácter de la revolución para el MIR se entendía entonces como socialista, anti-imperialista y anti-capitalista a la vez, retomando el principio marxista-leninista que asumía que el camino para derrocar el régimen capitalista era la insurrección popular armada" 51 , sosteniendo "que el programa planteado solo podrá realizarse derrocando a la burguesía e instaurando un gobierno revolucionario dirigido por los órganos de poder de obreros y campesinos" 52

Lo que aquí nos importa mostrar es que cuando María reconstruye su historia la memoria militante cobra un carácter central. Como señalamos antes, las memorias más emblemáticas sobre el pasado reciente, orientadas por la denuncia de las violaciones a los derechos humanos, han tenido como efecto terminar con una suerte de silenciamiento sobre la experiencia militante. Lo contrario ocurre en este relato al ser invitada a contar su trayectoria política.

Ahora bien, el recuerdo de la militancia se hace relevando no sólo los objetivos políticos, sino una mezcla de diversos sentidos que incluyen lo valórico y afectivo. Como señala Ruiz, "la cultura opera como un sistema de significación a través del cual se vivencia y construye la experiencia social", por lo tanto, desde allí es posible comprender el "entramado valórico, ideológico y emocional que configuró la subjetividad revolucionaria de los 60 y 70", desde un nuevo enfoque que supera la exclusiva adhesión racional al proyecto político. De acuerdo a lo anterior, "estas definiciones permiten comprender las prácticas culturales cotidianas como el escenario donde se despliega y construye un determinado tipo de prácticas políticas, visibilizando así dimensiones menos evidentes de la experiencia militante" 53 . No de otra forma es posible aproximarse a la comprensión del sujeto político y su militancia:

se entendía de que lo que nosotros trabajamos era esta propuesta que... que abarcaba lo económico, abarcaba lo social y también había una propuesta valórica de un país y de lo que el ser humano de ese país tenía que ser y bueno nosotros en este caso era fundamental todo lo que... los planteamientos y los escritos del Che, el Che eh... fue un... en términos valóricos, en términos de, de la propuesta de un "hombre nuevo", de una nueva sociedad, o sea esta nueva sociedad que tenía estos nuevos parámetros económicos no podía hacerse si no había un "hombre nuevo". Por lo tanto, la propuesta

\footnotetext{
50 Igor Goicovic, Los trabajadores al poder. El Movimiento de Izquierda Revolucionaria (MIR) y el proyecto revolucionario en Chile (1965-1994), Concepción, Escaparate Ediciones, 2016, 37.

${ }^{51}$ Pedro Naranjo et al. (ed.), Miguel Enríquez y el proyecto revolucionario en Chile. Santiago: LOM Ediciones, 2004, 101.

${ }^{52}$ Ibid., 105.

${ }^{53}$ Ruiz, op. cit., 167-168.
} 
valórica era la que cruzaba y de ahí está el tema de solidaridad y el tema de lo colectivo, o sea no había nada que no se pudiese hacer sin una participación colectiva y uno se expresaba a través de ese colectivo y se identificaba en ese colectivo. Entonces eso le daba como mucha fuerza y uno se sentía muy cercana a la gente con quien estaba trabajando porque nos sentíamos que estábamos en el mismo proyecto, estábamos haciendo lo mismo y en la medida en que nosotros nos pudiésemos conjugar, estos proyectos se podían también, podían cuajar, cosa que, en términos haciendo un paralelo, hoy día es absolutamente distinto, cada cual tiene una propu...un proyecto distinto, cada cual tiene una propuesta de individuo distinta y por lo tanto de allí es imposible, nos cuesta mucho hablar de lo colectivo

Como bien señala Ruíz, las expectativas del "hombre nuevo" guevarista llenaba de mística, pero también de exigencias a quienes adherían a la revolución. El proyecto político revolucionario no sólo buscaba la transformación de la estructura económico-política "sino también la construcción de una nueva moral que liberara a los hombres (y mujeres) del estado de alienación al que se encontraban sometidos bajo el modelo capitalista", ya que el socialismo no era una teoría económica y, por tanto, no era un mero método de repartición sino, por el contrario, era "un sistema creador de nuevas conciencias y subjetividades" 54 . Esta moral es adquirida a través "de la autoeducación y la toma de conciencia del nuevo conjunto de valores que le dan sentido a la comunidad revolucionaria" ${ }^{25}$, comprendiendo a la moral de los militantes como "una argamasa entre lo que se esperaba del combatiente como vanguardia y especie de "adelanto" de ese hombre nuevo por venir y las exigencias que el combatiente tenía por las características de la lucha por la que había optado"56.

Así, lo que adquiere protagonismo en el acto de rememoración es la dimensión ideológica de la narradora, consolidando su identidad política en diálogo con el presente:

cuando el año 67', 68' se provoca un gran revuelo y es la Reforma Universitaria y van unos estudiantes (...) estaba...una sociedad, que estaba bastante definida por la, una concepción clara de los derechos más que politizadas, diría yo, que hoy día puede ser politizada pero hoy día decir politizado a mí me da cosa por el tema político, hoy en día está tan ligado a la corrupción. Entonces en ese momento, hace quizás... 20 años, habíamos dicho que estábamos todos politizados, pero hoy día me da un poco de pudor decir eso, entonces mejor digo que teníamos, estábamos más claros en temas de la defensa de los derechos

María muestra aquí lo planteado por diversos autores y autoras -entre ellos Jelin ${ }^{57}$ respecto de cómo las rememoraciones del pasado se hacen en función de los desafíos del presente: en este caso la memoria militante se conecta con la deslegitimación de la política partidaria en el Chile de la postdictadura.

Junto con eso, adquiere gran relevancia el recuerdo de la reforma universitaria,

\footnotetext{
${ }^{54}$ Ibid., 164.

55 Vidaurrázaga, 2012, op. cit., 38-39.

${ }^{56}$ Idem.

${ }^{57}$ Jelin, 2002, op.cit.
} 
dando cuenta de la importancia de las movilizaciones estudiantiles en la politización de los jóvenes de la época, puesto que, en las luchas por la autonomía y la extensión universitaria, se movilizaron compromisos transformadores de la sociedad que buscaban superar la desigualdad social. En ese sentido, este hito es fundamental para comprender los marcos sociales de las memorias documentadas en la región de Valparaíso, en donde muchas jóvenes estudiantes mujeres se involucraron o se contactaron con experiencias concretas de participación política que se imbricaron con militancias en proyectos políticos de la izquierda revolucionaria desde el ámbito universitario, lugar entendido como espacio altamente denso en la socialización política de las jóvenes.

ya cuando entro a la universidad y entro con esta decisión de plantearme esta posibilidad de yo hacer cosas para poder, eh... para que se pudiese concretizar el proyecto popular que tenía Allende y bueno, llego a una universidad donde está en plena reforma, entro afortunadamente a una carrera que yo no sabía lo que me iba a enriquecer como persona y en ese momento tampoco la orientación universitaria de las carreras era tan definida. Yo era la primera generación de mi grupo familiar que entraba a la universidad, por lo tanto entrar a la universidad ya era gran cosa y daba lo mismo donde entrar (...) y me incorporé a la Escuela de Trabajo Social de la Católica, eh... realmente fue... para mí, fue un acierto muy grande, fue muy enriquecedor porque en ese momento las escuelas de servicio social o de trabajo social estaban planteando una línea en América Latina, que era el trabajo hacia el... trabajo poblacional, hacia el pueblo en concreto, o sea, un profesional se debe a, tiene que responder por la educación que se entregó a un compromiso social y eso era en este caso trabajo social, trabajaba con la gente más pobre, la gente con más necesidades, la gente con más carencias y además también dentro de, no de una forma asistencial sino que buscando una organización que permitiese transformar la sociedad eso era lo que se decía en la escuela y esa... y nos evaluaban por eso. Como nosotras nos insertábamos en los distintos sectores sociales donde se podía transformar la sociedad que eso era por ejemplo en el sector sindical, en el sector obrero, en el sector campesino, eh... organizaciones campesinas $y$ en el sector poblacional fundamentalmente con la gente que estaba sin vivienda.

Para entender la relevancia que tiene la conjugación ente participación estudiantil universitaria y militancia en la izquierda revolucionaria, conviene traer a la memoria algunos antecedentes. El MIR, en su "Programa" de 1965, frente al problema campesino señala que "nuestro país semi-colonial, tanto por su estructura económica como por su dependencia del mercado mundial, necesita enfrentar tareas básicas: la liquidación del imperialismo y la revolución agraria. Tras estas medidas deben movilizarse a la mayoría nacional compuesta por obreros, campesinos y sectores medios empobrecidos". La revolución agraria significaba "expropiación”, proceso que comprendía "la entrega a los campesinos que las trabajan, entrega que podrá ser individual o colectiva de acuerdo a las condiciones específicas de cada zona, e irá acompañada de ayuda técnica, de créditos, maquinarias, semillas y demás medidas encaminadas a elevar el nivel de productividad del 
agro" $"$.

La muerte en combate del "Che" en 1967, reafirmó ese clima de época que venía gestándose en el MIR, donde una vanguardia del pueblo despertaba su conciencia de clase mediante la elaboración del pensamiento y la praxis revolucionaria expresada en la lucha armada contra la burguesía y el imperialismo. El apoyo de las masas junto con el poder militar eran los dos elementos sin los cuales no podía tener éxito una guerrilla ${ }^{59}$. Consecutivamente, el partido se entendía como:

"un partido de vanguardia del proletariado y el pueblo chileno que tiene por objetivos la defensa de sus intereses inmediatos, y la lucha por la Revolución Proletaria y Popular para establecer en nuestra patria la más amplia democracia revolucionaria de masas, construir el Socialismo y alcanzar la sociedad Comunista sin clases"60

A partir del bienio 1967-1968, la radicalización política de los jóvenes facilitó a la izquierda revolucionaria la germinación de un espacio idóneo para alcanzar un grado significativo de inserción de masas, lo que se expresó inicialmente en el sector estudiantil, en la denominada "reforma universitaria"61 y posteriormente en el ámbito sindical ${ }^{62}$.

La compleja imbricación entre universidad y sociedad da cuenta de las tensiones propias de la época en torno a los problemas de desarrollo del continente y la efervescencia política de los jóvenes por encontrar un espacio de participación política que diera lugar a sus inquietudes mediante el involucramiento en el proceso del gobierno de la Unidad Popular, espacio que María encuentra inicialmente en los "trabajos voluntarios" de la universidad desarrollados en las comunidades de Colliguay, y que luego canalizará en la "práctica profesional" y en el quehacer político en el sector de Los Andes-Quillota. Sin embargo, es importante dar cuenta previamente de la relevancia de uno de los tantos efectos de la "reforma universitaria" de 1967: el "Movimiento de Reconceptualización del Trabajo Social" en América Latina, del que María es testigo de primera fuente:

yo creo que las herramientas que a mí me han acompañado toda la vida y me han permitido crear, me han permitido trabajar y... creo que trabajar bien han sido los elementos metodológicos y básicos que me dio la universidad en ese periodo. Ahora estamos hablando de un periodo, donde se buscaba transformar la sociedad, por lo tanto, las materias tenían que ver con eso (...) "El Capital” (...) en Economía Política. En metodología estaba todo el trabajo de Paulo Freire, Educación popular, que era la metodología transformadora que nosotros nos apoyaba en términos de trabajo social.

\footnotetext{
${ }^{58}$ MIR, Programa, 1965, s.n., 2.

59 Alondra Peirano, "Revolución y lucha armada: ¿una relación necesaria? El Movimiento de Liberación NacionalTupamaros y el Movimiento de Izquierda Revolucionaria en sus inicios (1965- 1973)", Revista Encuentros Latinoamericanos, 3:9, 2009, 3.

${ }^{60}$ MIR, Estatutos, 1965, s.n., 1.

61 Jaime Rosenblitt, La reforma universitaria (1967-1973), Santiago: s.n.; Carlos Huneeus, La reforma universitaria. Veinte años después, Santiago, CPU, 1988.

${ }^{62}$ Eugenia Pelieraki, ¡La revolución ya viene! El MIR chileno en los años sesenta, Chile, Santiago, LOM Ediciones, 2014.
} 
Eh... estaba también Medicina Social, que se veía todo el tema de epidemias y todo el mapa de la salud en Chile (...) era lo que el Chile necesitaba (...) en este caso, la... el trabajo se hacía en tres ámbitos, que era el ámbito campesino, que era el ámbito sindical-obrero-fábrica y que era el ámbito de pobladores (...) yo elegí el ámbito campesino y lo elegí fundamentalmente porque con este deseo de poder aportar al gobierno de Allende eh... fui a los primeros trabajos voluntarios que se hacen en la Católica (...) en Colliguay (...) fue tremendamente motivador y fue un golpe de conocer así de repente una realidad que yo no la conocía, la había escuchado, pero distinto era conocerla porque era del liceo a la casa, de la casa a la universidad y de la universidad a la casa y algunas fiestas, carretes pero que no tenían mayor trascendencia, pero ir a trabajar todo un verano con los campesinos en Colliguay, o sea llega de golpe, a mí me llegó de golpe que toda la pobreza que había en un sector tan amplio de la población, donde los más afectados era los niños eh... y bueno y eso hace que yo, cuando terminé el trabajo voluntario... me decido a trabajar... como... trabajadora social con el sector campesino (...) eran dos universidades que estaban dando la línea en todo lo que era trabajo social y llegaban profesores de toda América Latina a trabajar en la Católica de acá de Valparaíso y llegaron unos brasileños que eran pero expertos en metodología, que eran los Faleiros, que aún hoy día ellos tienen libros publicados en Brasil que tienen que ver con la educación popular, bueno, ellos eran profesores, estaban (...) Cardoso que también había escrito bastantes libros, habían un profesor de sociología que era el que me guiaba a mí la tesis final, y él había trabajado en ese momento con movimiento campesino y había sido uno de los miembros de una de las columnas del "Che". Entonces era un contexto donde se hablaba de una América Latina (...) Bueno este profesor era el que me guiaba la tesis campesina porque mi proyecto se llamaba "Poder popular en el campo" y que estaba centrado fundamentalmente en todo lo que era la reforma agraria y los distintos ámbitos de organización político, económico, social que se daba en el campo.

A partir de este relato es posible comprender que la universidad no es sólo un espacio de formación política en el ámbito de las organizaciones estudiantiles (como en otros relatos incluidos en la investigación más referidos a militancias urbanas) sino también un espacio de formación académica muy vinculado a los desafíos del país. En ese sentido, resultan relevantes las referencias a las transferencias producidas en torno a intelectuales como Vicente de Paula Faleiros ${ }^{63}$ o Fernando Henrique Cardoso ${ }^{64}$. A través de ellos, los estudiantes se introducían en la realidad latinoamericana y chilena para perfeccionarse profesionalmente y desempeñar algún rol dentro de las transformaciones en curso en los territorios y comunidades más necesitadas, lo que en el caso de María se da con comunidades campesinas en el territorio “interior” de la región de Valparaíso.

En términos de género, no es menor que las mujeres en estos años ingresen a las universidades de manera significativa, al menos en ciertos sectores, lo que les permite

\footnotetext{
${ }^{63}$ Vicente de Paula Faleiros, trabajador social brasileño, es uno de los teóricos del "Movimiento de Reconceptualización del Servicio Social en América Latina", experiencia canalizada en Chile al interior de la Escuela de Trabajo Social de la Universidad Católica de Valparaíso como resultado de la "reforma universitaria" de 1967, revisar: Vicente de Paula Faleiros, Trabajo social e instituciones, Buenos Aires, Humanitas, 1992.

${ }^{64}$ Fernando Henrique Cardoso, elaborador de la "teoría de la dependencia", revisar: Fernando Henrique Cardoso y Hugo Falleto, Dependencia y desarrollo en América Latina, Buenos Aires, Siglo XXI Editores, 1977.
} 
establecer una vinculación con la política que de otro modo habría sido más difícil. Podemos relacionar dicho fenómeno con lo planteado por Bertaux ${ }^{65}$, cuando señala que hay momentos donde líneas paralelas se cruzan en una trayectoria, en este caso, los estudios y la formación política. A su vez, no es menor cómo el ingreso a la universidad cambia la movilidad espacial - de la casa al liceo y de este a la casa- en término sociopolíticos: la universidad para las mujeres militantes no fue solo el acceso a la educación superior, como lo enfatizan las memorias dominantes sobre los cambios de género a finales de los años 60', fue para muchas el ingreso a la vida política y a la política revolucionaria.

Sin embargo, en sus rememoraciones es en el campo donde se encuentra con una realidad que la marca como ninguna otra. Con ello pasamos al tercer eje de las memorias subalternas: las memorias locales.

[en Colliguay] me tocó ver a muchas mujeres solas con muchos hijos y tremendamente alejadas, lo más que me impactó fue una mujer que vivía con tres hijos, muy muy lejos del lugar de donde habían más viviendas en Colliguay y ella tenía un defecto que no hablaba bien porque tenía un frenillo y los tres hijos que eran pequeñitos hablaban exactamente igual que ella, incluso los dos más chicos no tenían frenillo pero hablaban igual que su madre, además en ese momento los niños eh... estaban, los criaban en un cajón, entonces eran los cajones frutales los que servían para que los niños estuviesen ahí su primer tiempo y después los mismo cajones que se les ponían barandas y los niños eran, les permitían aprender a pararse y a caminar (...) Si de cierto hoy día la tenemos absolutamente inversa porque hoy día lo individual es lo que vale, en ese momento era lo colectivo si al colectivo le iba bien a todos nos iba bien y eso es lo que yo sentía y en ese colectivo me identificaba. Y yo creo que es algo que me marcó porque hasta el día de hoy, yo sigo buscando lo colectivo y cada vez es más difícil de encontrar o no sé si ya existe o no

Si bien María señala que esa realidad ya la había visto en las poblaciones urbanas, no se iguala con la miseria que conoció en el campo, lo cual configura el deseo inicial que motiva su participación política, "un poco romántico de querer transformar la sociedad para mejor", como señala ella, pero que se vuelve un elemento fundamental que le permite buscar intensamente un proyecto político donde "se hablaba de la solidaridad, que se hablaba de la igualdad y que tenía el valor de lo colectivo" para luchar porque "esta transformación fuese [posible] realmente".

Esto se puede vincular con lo que ya ha señalado Oberti ${ }^{66}$ sobre el impacto que genera conocer la miseria como una estimulación para el ingreso a la militancia revolucionaria (lo que en Argentina tenía que ver con la vida en los barrios marginales), pero que aquí nos muestra una articulación entre memoria y género puesto que ella enfatiza particularmente la feminización de la miseria en el campo como lo que más la impactó.

Por otro lado, la cita anterior vuelve a mostrar cómo desde el ejercicio de hacer

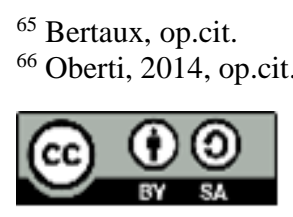


memoria María interroga el presente de la sociedad chilena por su exacerbado individualismo. Esto se condice con lo que Elizabeth Jelin identifica, comparativamente con otros países del Cono Sur, como la principal consecuencia de la dictadura chilena: la naturalización del neoliberalismo ${ }^{67}$.

El presente actual parece ser clave para que María se detenga en extenso en la descripción del contexto de politización de los jóvenes que había en la época y que tensionaba la vida universitaria interpelada por las necesidades de ese presente-pasado, cuestionando su subjetividad por las interrogantes del involucramiento y el compromiso. Así profundiza sobre su experiencia en la Escuela de Trabajo Social de la Universidad Católica de Valparaíso al inicio del gobierno de la Unidad Popular, señalando que:

ese era el contexto que había en la universidad, un contexto de mucho compromiso y también de mucha efervescencia porque obviamente en la medida que se iban aclarando los proyectos políticos (...) y con estos profesionales que salían a transformar la sociedad uno entraba al casino y las escuchaba y había una asamblea y la gente se paraba en la mesa a plantear su proyecto, su propuesta y era, era una agitación y una entrega de conocimiento constante en términos de una situación que estaba pasando y asumiendo posturas y las posturas eran de compromiso, de compromiso de un quehacer y de tareas concretas (...) entonces eso significó de que yo en la universidad empecé ya a estudiar y dentro de la escuela con esto de, de ubicar la profesión, lo que llamamos el materialismo histórico, el materialismo dialéctico, la teología de la liberación y la educación popular en términos de transformar la sociedad, empiezo también a estudiar y a reconocerme en lo que fue la Revolución Cubana, el movimiento de Vietnam, que estuvimos en los primeros años una participación bastante grande como movimiento estudiantil en el tema de Vietnam y la guerra de Estados Unidos (...) ahí encontré que plasmaba realmente mi sentido y mi mirada en lo que era mi vida y en lo que era el país porque era raro, pero en ese momento se miraba a uno, pero al mirarse a uno también miraba una propuesta de país, una participación activa

La narración de María nos permite acercarnos a una cierta intensidad de la vida universitaria en Valparaíso cruzada por los procesos políticos y sociales de Chile, Latinoamérica y el mundo, como la Revolución Cubana o la guerra de Vietnam, pertenencia identitaria que se corresponde con las otras trayectorias políticas de mujeres militantes y ex presas políticas que incluimos en el estudio. Esto permite entender que las memorias locales no por locales dejan de dialogar con otras escalas nacionales y globales.

\section{Rememorando la experiencia del Movimiento Campesino Revolucionario entre Los Andes y Quillota durante la Reforma Agraria de la Unidad Popular}

Teniendo tres áreas para desarrollar su tesis y práctica profesional en Trabajo Social, e influenciada por la experiencia de lo que había sido el trabajo en Colliguay, María se va a

\footnotetext{
${ }^{67}$ Agradecemos las conversaciones sostenidas con Elizabeth Jelin sobre este tema, en el marco de su participación en el citado proyecto Fondecyt, durante noviembre del 2016.
} 
trabajar con los campesinos, específicamente al sector de Los Andes durante el año 1970.

porque ir a Los Andes significaba estar tres días en Los Andes y poder trabajar sin tener que explicarle a nadie donde iba, cuando iba, a qué hora llegaba y en la casa como era... yo fui la primera generación que entró a la universidad por lo tanto el estudio era sagrado y lo que decían los estudios era lo que se hacía. Y estratégicamente yo dije que para poder seguir estudiando tenía que irme a trabajar a Los Andes, nadie dijo nada, nadie me puso ninguna dificultad y partíamos con un grupo de tres compañeras más, partíamos a Los Andes el día miércoles a las 12:30 hrs. del día, tomábamos el tren al frente de la Católica y llegábamos el sábado, el domingo de vuelta de Los Andes (...)

En términos de género, llama la atención como esta decisión es narrada como una forma de ganar autonomía e independencia porque así nadie podría ponerles dificultades. Hay que recordar que ello ocurre en un contexto donde todavía las mujeres jóvenes, en este caso estudiantes universitarias, carecían de los mismos grados de libertad que sus compañeros varones para moverse fuera del espacio familiar y doméstico. Había que dar explicaciones, por lo que la práctica profesional opera como una suerte de salvoconducto.

Asimismo, teniendo un compromiso tan alto con lo que estaba haciendo junto con sus compañeras, María señala que utilizaban "más de la mitad de la semana solamente en trabajar en...viendo el tema campesino". Para conocer "cómo era la vida de los campesinos" debían en su primera práctica de 6 meses incorporarse a algún asentamiento de los que estaban en el proceso de Reforma Agraria, integrándose a esta reforma como trabajadoras, cumpliendo "con el mismo horario de ellos y haciendo las mismas cosas de ellos". La Reforma Agraria, en el contexto del Gobierno de la Unidad Popular, supone agudizar el proceso de transformaciones iniciado por Frei Montalva con los asentamientos, incorporando las expropiaciones de las haciendas del latifundismo como prioridad. Si bien es cierto que las tomas de terreno se agudizaron con la asunción de Allende, resulta importante considerar lo que señala Fontaine al indicar que dicho proceso se profundiza cuando el gobierno dicta el decreto supremo N481 en el año 1970 que crea los "consejos campesinos" para promover el "poder popular", en donde "se supone daría una participación decisiva a los trabajadores en la reforma agraria". Sin embargo, ante el análisis de este autor, "ello sería una contribución más a la anarquía que se produce en la agricultura" 68 .

Para entender esto, hay que recordar que el latifundismo es el fenómeno central de la historia agraria del país siendo la institución de más larga duración en Chile, caracterizado por la tenencia de grandes tierras en una misma familia o persona, y la consecuente concentración territorial y social. Como señala Bengoa, "la hacienda ha sido la expresión más clara de desigualdad social en la sociedad chilena del siglo XX"69. Más

\footnotetext{
${ }^{68}$ Arturo Fontaine, La tierra y el poder: Reforma agraria en Chile (1964-1973), Santiago, Zig-Zag Ediciones, 144. Como se desprende de la lectura de este autor conservador, la finalidad de la Reforma Agraria "no es ya levantar el nivel de vida de los campesinos" sino quitarle el poder a los terratenientes.

${ }^{69}$ José Bengoa, Haciendas y campesinos. Historia social de la agricultura en Chile, Tomo II, Santiago, SUR, $1990,15$.
} 
recientemente, Robles da cuenta que:

La expansión de la agricultura chilena se verificó desde mediados del siglo XIX a través de la transformación del sistema de hacienda en Chile Central, la ocupación y extensión de la frontera agrícola sobre el territorio del pueblo mapuche en la región de La Frontera y la colonización de una región periférica con inmigrantes extranjeros (provincia de Llanquihue). En Chile central la expansión agraria fue el resultado de la estrategia de los grandes hacendados para aumentar las exportaciones de trigo a California, Australia y, sobre todo, Inglaterra en una serie de ciclos exportadores entre 1850 y 1880 (Sepúlveda, 1956). En respuesta al alza de los precios internacionales, los terratenientes aumentaron la producción extendiendo la superficie cultivada, especialmente en las haciendas cercanas a los grandes centros urbanos y los puertos de embarque. La expansión también tuvo lugar en haciendas que se especializaron en ganado de calidad, productos lácteos y forrajes para el mercado interno, cuyos dueños aumentaron el cultivo de alfalfa y trébol en tierras regadas y de secano. Además, desde la década de 1880, a medida que las exportaciones de trigo disminuían, la agricultura de Chile central se diversificó gracias a la modernización de la viticultura, especialmente en un sector de grandes "viñas francesas", así como la formación de un sector frutícola comercial. La expansión agraria estuvo además asociada a la formación de unidades de producción de tamaño más adecuado para su administración y, a juzgar por el aumento del área cultivada, explotadas de manera más eficiente. Desde mediados del siglo XIX, con la intensificación del mercado de tierras, las grandes haciendas (1000-5000 has.) aumentaron su número pero se redujeron en tamaño; en cambio no sólo aumentó el número de las propiedades medianas (51-200 y 200-1000 has.), sino su tamaño medio y su porcentaje del área agrícola, como el departamento de Caupolicán, un área representativa de la agricultura de Chile central"70.

La situación de la sociedad agraria en el país, y más específicamente en el Valle del Aconcagua, estuvo caracterizada por una estructura hacendal que establecía diferenciaciones según empresas y zonas productivas. Progresivamente las exportaciones de cereales fueron transformando la hacienda ganadera -por lo general, de estructura abierta y con límites poco precisos- en una explotación multiproductiva, que combinaba cereales, la ganadería y otras plantaciones como las viñas. La riqueza del Valle del Aconcagua hizo que se desarrollara una agricultura más intensiva que en el resto del país, expresada en la especialización en la producción de frutales y hortalizas, lo que explica el establecimiento de la conservería para surtir al mercado interno y la exportación. Debido a la calidad de las tierras, el campo se fue subdividiendo progresivamente en chacras y pequeñas propiedades altamente productivas en los sectores de Quillota, Limache, La Cruz, San Felipe y Los Andes. Sin embargo, esta no era una situación homogénea en el Valle, ya que en San Felipe, por ejemplo, se encontraba una subdivisión, especialización y modernización de la propiedad y sus cultivos, pero en áreas como Catemu o Putaendo predominaba, aún a mediados del siglo $\mathrm{XX}$, un tipo de latifundio con sistemas de

\footnotetext{
70 Claudio Robles, "Expansión y transformación de la agricultura en una economía exportadora. La transición al capitalismo agrario en Chile (1850-1930)", Historia Agraria, 29, 2003, 46-47.
} 
inquilinaje tradicional ${ }^{71}$.

Es en ese contexto donde se incubó la Reforma Agraria de los años sesenta. Según Bengoa, los campesinos fueron progresivamente conquistando tierras y recursos a lo largo del siglo XX, primero aumentando las regalías de tierra y los talajes, presionando al latifundio desde dentro para buscar transformarse en pequeños agricultores independientes. Las reformas, asentamientos y expropiaciones entonces venían a decretar la prescripción legal de un latifundismo practicado por la oligarquía chilena que se enriquecía a costa de la explotación del campesinado en una vocación consumidora y no redistributiva ${ }^{72}$. Sin embargo, a pesar de ello, la desigualdad en las que vivía la población rural era brutal, ya que mientras los latifundistas se enriquecían, el campesinado subsistía económicamente con salarios estancados y en la insalubridad más inhumana de los rancheríos, desarrollando una vida familiar con altas tasas de natalidad, mortalidad infantil y analfabetismo.

Frente a todo lo anterior, la Caja de Colonización Agrícola bien poco pudo hacer dados los escasos recursos con que contaba. Si bien los Frentes Populares atacaron el problema, luego retrocedieron al tener que pactar con los terratenientes por la débil fuerza político-social que poseían. Según Affonso $^{73}$, no fue sino con la Ley No15.020 promulgada en el año 1962, durante el gobierno de Frei Montalva, que la Reforma Agraria comenzó a "crear una conciencia nacional respecto a la necesidad de efectuar cambios profundos en la forma en que estaban organizados los sistemas de producción y propiedad en la tierra"74 y desarrollar las expropiaciones del latifundio y los predios mal trabajados, entregándolos a los campesinos bajo una orientación asociativa expresada en el fortalecimiento de sus organizaciones en sindicatos y cooperativas. Como se sabe, en ese proceso tuvo un rol protagónico el Estado desde el Instituto de Desarrollo Agropecuario (INDAP) ${ }^{75}$. Se estima que en $1965^{76}$ el INDAP logró asesorar a 488 organizaciones sindicales (con o sin personalidad jurídica). A partir del año 1967, con la promulgación de la Ley $\mathrm{N}^{\circ} 16.625$, todos los trabajadores y empleadores agrícolas vieron reconocidos sus derechos a la sindicalización campesina ${ }^{77}$. Entre 1968 y 1973 se crearon 500 nuevos sindicatos, lo que dio lugar a la conformación de federaciones y confederaciones a nivel nacional. Según Gómez $^{78}$, la tasa de sindicalización en el campo era prácticamente de un $100 \%$ en el año 1973.

El presidente Allende plantea la Reforma Agraria como un "proceso simultáneo y complementario con las transformaciones generales que se desea promover en la estructura

\footnotetext{
${ }^{71}$ Bengoa, 1990, op. cit, 71.

72 Ibid., 19.

${ }^{73}$ Almino Affonso, Trayectoria del Movimiento Campesino Chileno, Santiago, ICIRA, Vol. I; 1970.

${ }^{74}$ Corporación de la Reforma Agraria, Reforma agraria chilena 1965-1970, Santiago, CORA, 1970, 101.

${ }^{75}$ Fernando Baeriswyl, Ángel Sartori, José Guzmán, Francisco Larenas, Reforma Agraria y Desarrollo Rural en Chile. Mejoramiento de la Economía Social de los Predios, s.n., 2006.

${ }^{76}$ Rodrigo Medel, Movimiento sindical campesino en Chile (1924-2000), Santiago, CIPSTRA, 2013.

${ }^{77}$ Francisco Walke, La legislación laboral campesina, evolución y proposiciones, Santiago, Desarrollo Campesino SA, 1983.

${ }^{78}$ Sergio Gómez, “Organización campesina en Chile: reflexiones sobre su debilidad actual”, Revista Austral de Ciencias Sociales, 6, 2002.
} 
social, política y económica del país”, otorgándole un carácter de transformación estructural y de relevancia revolucionaria al señalar que "el gobierno de la Unidad Popular se ha planteado como objetivo transformar la estructura capitalista subdesarrollada y dependiente de la sociedad chilena, creando las condiciones que la lleven hacia el socialismo" 79 , otorgándole a la reforma un carácter de máxima relevancia para la política del gobierno y de las transformaciones revolucionarias para el período. Con más del $60 \%$ de la tierra y entre el $80 \%$ y $90 \%$ del crédito en las manos del latifundismo, el gobierno de la Unidad Popular realizó una profundización del proceso de la Reforma Agraria, lo que queda reflejado en la expropiación de 4.401 predios con 6,6 millones de hectáreas entre los años 1971 y $1973^{80}$. Toda la política agraria de este período puede sintetizarse en la modificación del sistema de tenencia de la tierra, del sistema de interrelaciones económicas entre la agricultura y el resto de la economía, de la participación campesina en el proceso de cambios y la reorientación de la estructura productiva junto con la superación de la postergación y segregación de grupos significativos (población mapuche y comuneros del Norte), asegurando una participación efectiva en las diferentes políticas de gobierno. Como señala Bengoa, las transformaciones producidas por la Reforma Agraria "lograron conmover los cimientos en que se sostenía la producción y sociedad rural. El latifundio fue expropiado casi completamente y destruido el sistema de haciendas sobre el cual descansaba la organización económica y social del campo" 81 . campesino:

María nos introduce en esas modificaciones radicales al sistema tradicional

El "Asentamiento La Golondrina" de Los Andes (...) empezaba trabajando en la lechería que había que levantarse a las 5 de la mañana, a sacar leche y era el horario que tenía el equipo de trabajo campesino en la lechería y después nos incorporábamos a cuidar los frutales que era un asentamiento que plantaba duraznos, duraznos, me parece que se llamaba "Reina Cristina", que son los duraznos de exportación. Entonces nosotros hacíamos esos primeros 6 meses, el mismo trabajo que hacían ellos, es decir, y además, nos quedábamos allá por lo tanto conocíamos, los visitábamos en sus casas eh... estábamos en sus actividades, sus cumpleaños, estábamos los tres días de la semana viviendo con los campesinos eh... en un, en ese momento vivíamos en un galpón que éramos cuatro mujeres las que hacíamos esa práctica que viajábamos de la Católica hacia allá (...) al semestre siguiente, ya nuestra práctica era del grado de organización, es decir, una vez conociendo las necesidades y las formas de vida de los campesinos ya podíamos trabajar en lo que era la forma organizacional, que eran los sindicatos campesinos o la estructura que ellos se daban de acuerdo al asentamiento y estoy en este trabajo, bueno entonces tal como comentábamos, había mucho que se permitiera esta formación real y eso significaba un proyecto político que tenía que manejar el tema del poder y dentro de eso el... por el quehacer mismo y la práctica donde yo estaba lo que a mí me pareció más certero, era el proyecto y las propuestas que tenía el MIR en este caso, especialmente para el movimiento campesino.

\footnotetext{
${ }^{79}$ Salvador Allende, Perspectivas sobre la reforma agraria, Chile, INDAP, 1972, 7.

${ }^{80}$ Jaques Chonchol, "La Reforma Agraria en Chile 1964-1973”, El Trimestre Económico, Santiago, 43:171, 1976.

${ }^{81}$ José Bengoa, El campesinado chileno después de la reforma agraria, Santiago, SUR, 1983, 9.
} 
Durante el gobierno de la Unidad Popular, el MIR puso el acento en la consolidación de una "fuerza social revolucionaria" 82 , donde los "frentes de masas" adquirieron una dimensión estratégica como origen y base de la construcción del poder popular. Estos frentes intermedios fueron los espacios sociales desde donde el MIR consolidó, desde el año 1970, el apoyo del pueblo hacia la causa revolucionaria. A partir de la necesidad de involucrar a amplios sectores sociales en la lucha política, desde el MIR se creó el Frente de Estudiantes Revolucionarios (FER), el Movimiento Universitario de Izquierda (MUI), el Movimiento Campesino Revolucionario (MCR), el Frente de Trabajadores Revolucionarios (FTR) y el Movimiento de Pobladores Revolucionarios (MPR), entre otras estructuras. La tesis del poder popular sostenía que la acción políticosocial debía llevarse a cabo principalmente mediante la toma de terrenos por parte de campesinos y pobladores y a través de la toma de fábricas por los trabajadores. Desde 1970 al 1973, la radicalización de la lucha de masas se consolidó en espacios de "poder dual" como resultado de las elaboraciones teóricas de la Comisión Política y de los aportes de Miguel Enríquez en estrecha articulación con las experiencias de masas desplegadas por el partido en la base del movimiento popular ${ }^{83}$. Según la caracterización del periodo, tanto los Comandos Comunales como los Cordones Industriales eran los espacios político-sociales estratégicos para la consolidación de la revolución socialista en Chile ${ }^{84}$.

En definitiva, hasta ese momento el MIR trabajó en lo que se denominó "la fase prerevolucionaria", comprendida por la formación de un partido de cuadros de rápido y exponencial desarrollo, la acumulación de fuerza social, política e ideológica a través de los denominados frentes intermedios y la preparación de movimientos de masas y de la organización partidaria para el inevitable enfrentamiento armado con la burguesía ${ }^{85}$.

La vinculación de María con el MIR se da en el marco de su práctica profesional en el territorio rural de Los Andes en los asentamientos "La Golondrina" y "Reina Cristina". María desarrolló el trabajo productivo de cualquier campesino que en estos asentamientos se relacionaba con la producción de los lácteos y las frutas de conserva de exportación. Posteriormente debía trabajar en el área organizacional de los asentamientos, y allí lo obvio en ese momento era hacerlo desde la participación en los sindicatos campesinos. En esas dinámicas cotidianas de la producción de los asentamientos, María rememora su pasado y el de sus compañeras de universidad como un momento en que observaban, aprendían y se vinculaban al trabajo campesino, pero habría que acotar que era el trabajo fundamentalmente masculino. Como ha mostrado Tinsman, la vida de las mujeres y las relaciones de género fue también impactada por la Reforma Agraria de un modo que no suele ser problematizado en las reconstrucciones que posteriormente se han hecho sobre lo

\footnotetext{
${ }^{82}$ Igor Goicovic, El internacionalismo proletario en el Cono Sur. La Junta Coordinadora Revolucionaria, un proyecto inconcluso, 2005.

${ }^{83}$ Miguel Amorós, Miguel Enríquez. Un nombre en las estrellas. Biografía de un revolucionario, Santiago, Ediciones B, 2014.

${ }^{84}$ Peirano, 2009, op. cit.

${ }^{85}$ Andrés Pascual Allende, El MIR Chileno. Una experiencia revolucionaria, Argentina, Cucaña, 2003.
} 
ocurrido en esos años ${ }^{86}$.

Como bien señala María, "la verdad es que el tema de la práctica se confundió absolutamente con el trabajo campesino". Trabajando con los campesinos en territorios distantes de las ciudades era difícil vincularse al MIR como partido; sin embargo, ella y sus compañeras lo logran a través de la propaganda, específicamente, mediante el periódico "El Rebelde". Al respecto, María señala:

cuando salía "El Rebelde”, parece que era cada 15 días, lo comprábamos y sacábamos de allí todo el programa campesino, lo discutíamos con este grupo de compañeras que éramos cuatro, eh... prácticamente nos lo aprendíamos de memoria, discutíamos los puntos, veíamos como lo planteábamos y empezamos a plantear las políticas campesinas del MIR a los distintos campesinos donde nosotros llegamos, donde conversamos, les discutíamos y así pasábamos aproximadamente dos meses (...) hasta que una base campesina de funcionarios de INDAP, se da cuenta que los campesinos estaban hablando con unas estudiantes de la Católica que estaban planteando exactamente el programa del MCR y empiezan eh... se comunican con la gente de la universidad. Había una compañera de la Escuela de Trabajo Social que era miembro, de un compañero del MIR, del regional, de la dirección regional y nos ubican que somos nosotras. En ese momento nos llaman y nos preguntan y nosotros dijimos lo que estábamos haciendo y lo que nos parecía y el compañero le dice a la compañera, nos llama y nos empieza a dar elementos de formación política para que nosotros realmente pudiésemos entender lo que era el MIR, lo que se planteaba y tener una conciencia más profunda de lo que estábamos haciendo y eso fue y como estábamos trabajando en el campo, ese fue nuestro ingreso al MIR

La narración de María nos permite comprender el vínculo del MIR con los territorios campesinos, dando cuenta del contacto que se establece entre los funcionarios de INDAP y gente de la Escuela de Trabajo Social de la Universidad Católica de Valparaíso, donde ella y su grupo de compañeras inician un proceso de formación política y pasan a constituir la unidad campesina del Movimiento Campesino Revolucionario (MCR) en la zona:

para mi es súper válido porque lo encontramos [al MIR] en un trabajo concreto, eh... campesino, en un frente [el MCR] como nosotros le decíamos en ese momento y tenía el valor de que entendíamos que en ese frente, esa política era correcta y por esa política nosotros nos decidimos y eso fue el ingreso al MIR (...) estuvimos trabajando así durante todo el resto del año y al final del año siguiente ya nos constituimos en la Unidad Campesina (...) y estaba a cargo de una mujer

Con relación a la política correcta que menciona María, la entendemos en la lógica de lo que el MIR había definido como prioridades: lo local e inmediato

La organización de las masas sólo puede hacerse a partir de sus reivindicaciones inmediatas y con ámbito local. No nos es posible en este momento pensar en

\footnotetext{
86 Tinsman, 2009, op. cit.
} 
estructurar un poder obrero o campesino en escala nacional; al contrario, es con base en la organización de la masa en sus centros de trabajo y de habitación que crearemos las premisas de una organización nacional, susceptible de plantearse, en la segunda etapa -la del gobierno popular- como un poder alternativo ${ }^{87}$

En este punto, es importante describir las conceptualizaciones de "militancia" y "base" en el diseño partidario del MIR, con la finalidad de comprender el universo de significaciones y alcances en la subjetividad y proyecto político revolucionario. Desde esa perspectiva, el militante se entiende como "un profesional de la revolución". Tal como lo señalan los documentos de la época, para el militante

su vida está definida por entero hacia la lucha, su existencia está centrada en la lucha revolucionaria y en el partido, y no puede existir disociación entre su vida privada y su vida política. La vida privada está subordinada a las exigencias de la vida partidaria y la lucha política revolucionaria. Nuestra profesión, nuestro oficio, es ser revolucionarios ${ }^{88}$

La base se entiende como "el núcleo con capacidad de dirección más pequeño del partido", siendo "el núcleo dirigente del partido en el seno de la clase obrera y las masas populares, asentado directamente en los frentes" ${ }^{\prime 9}$. Asimismo, existían bases de simpatizantes, aspirantes y militantes. Sin embargo, es importante entender que la base superaba la condición de agrupación de gente reunida con una finalidad política, ya que, como bien lo señala María, "sentíamos digamos, esta necesidad de estar juntos", ya que "ahí crecimos, que ahí nos nutríamos y además eh... creíamos realmente en lo que estábamos haciendo, por lo tanto, pasamos muchas cosas (...) pasábamos mucho frío, nunca teníamos plata, comíamos mal pero no se notaba en ese momento, todo era la construcción que estábamos haciendo”. Como señala Ruíz

la identidad cultural partidaria sobrepasa los elementos estrictamente ideológicos (...) la organización política existe en tanto comunidad humana en la que se cruzan los afectos y las ideas, las razones y las pasiones, lo privado y lo público, y en la que las acciones políticas son vividas, sentidas y pensadas de un modo particular $^{90}$

Como señala Oberti, los militantes de la nueva izquierda aceptan el sacrificio de renunciar o posponer lo individual por el proyecto político revolucionario por el "borramiento de sí en el colectivo", donde "la supervivencia en el colectivo, en el caso de que sobrevenga la muerte, aparece como un mandato, el único posible si quiere ser fiel al ideario revolucionario ${ }^{91}$. Eso es lo que Longoni llama "mandato sacrificial"92. Al respecto,

\footnotetext{
${ }^{87}$ MIR, Discurso del Secretario General del MIR a nombre de la Dirección Nacional, en Cautín el lunes $1^{\circ}$ de Noviembre de 1971 en Homenaje a Moises Huentelaf, héroe de la lucha campesina, Santiago (Biblioteca Nacional de Chile), $1971,5$. ${ }^{88}$ MIR, Manual $N^{o}$ 3: La base, Colección Miguel Enríquez, s.n.

${ }^{89}$ Idem.

${ }^{90}$ Ruiz, op. cit., 168.

${ }^{91}$ Oberti, Alejandra, Género, política y violencia. Vida cotidiana y militancia en las décadas del sesenta y setenta, Tesis para optar por el grado de Doctora en Ciencias Sociales, Buenos Aires: Universidad de Buenos Aires, 2011, 190.

92 Ana Longoni, Traiciones, Buenos Aires, Norma Editorial, 2007.
} 
Waldman señala que "el espacio de lo íntimo y lo subjetivo -esencialmente "femeninos"quedaban subordinados a la primacía de los intereses colectivos", por lo que la militancia significó "la construcción de una nueva forma de subjetividad" marcada por la lucha revolucionaria que busca transformar la sociedad "encarnando al hombre nuevo -en masculino-dotado de una nueva ética"93.

En ese marco es interesante dar cuenta de un proceso particular y poco estudiado a la fecha que dice relación con el ingreso a la militancia de organizaciones de la izquierda revolucionaria en Chile, algo que no sólo ocurría en el marco de la vida universitaria urbana y sus organizaciones estudiantiles, sino también en el campo entendido como un espacio de militancia y construcción política y social posible y, en este caso, protagónica. En ese sentido, es un hallazgo de esta investigación visibilizar el rol protagónico de las mujeres del MCR, donde en la Unidad Campesina eran dos hombres y tres mujeres, incluyendo a la jefa de la Unidad. Todas ellas eran de la misma universidad, incluyendo una académica. Sobre este liderazgo de su jefa, María nos dice que:

Era una mujer, era una compañera que estudiaba Agronomía, era una espectacular ella eh... súper rigurosa, súper disciplinada, súper seria, que nosotros eso nos gustaba mucho que el trabajo político y partidario tuviera una rigurosidad y una seriedad que nos daba la confianza, no sé de a donde sacamos eso, porque éramos jóvenes, pero eso nos parecía súper...eh... responsable. Que se llegaba a la hora, que no se faltaba a las reuniones, que las reuniones fuesen buenas y que la gente también fuese así como entre comillas seria y responsable pensábamos en ese momento, y nos vinculamos al MIR en la universidad porque como era un movimiento estudiantil era distinto (ríe), en cambio con los campesinos nos sentíamos que era mucho más concreto, que había que ser mucho más responsable, que no teníamos que patear la reunión y llegar a la hora y la primera jefa de unidad es una, fue una mujer, todavía aún hoy día nos vemos.

Esto es relevante ya que en los estudios de memoria en Chile sobre subjetividades y proyectos políticos revolucionarios no se ha destacado la participación de las mujeres en roles protagónicos de las organizaciones revolucionarias, sino que más bien se ha establecido un relato que, por lo general, sostiene una lectura de las problemáticas sobre "la maternidad, las relaciones de género, la disciplina interna, los mandatos que organizaban y estructuraban la vida diaria" 94 . Desde el caso argentino, en cambio, Oberti señala que "el PRT-ERP (y todas las organizaciones político-militares) contaban con una importante presencia de mujeres militantes, producto seguramente de una participación femenina en ascenso en todas las esferas sociales y políticas"95. En ese sentido, el relato de María es relevante en relación a lo planteado por Oberti, ya que rememora la participación de las mujeres en el MIR no como algo excepcional sino más bien "normal". En esto puede haber un reflejo de los cambios empujados por un emergente feminismo de los años sesenta y

\footnotetext{
93 Gilda Waldman, “Voces vivas de la militancia femenina en los 60' y 70': tensiones de la subjetividad", Taller de Letras, 48, 2011, 87-89.

${ }^{94}$ Ruiz, op. cit., 168-169.

95 Alejandra Oberti, "Las mujeres en la política revolucionaria. El caso del PRT-ERP en la Argentina de los años 70", Revista Internacional Interdisciplinar INTERthesis, 10:1, 2013, 10-11.
} 
setenta que "formaban parte del universo de sentidos y prácticas disponibles para una generación altamente movilizada y politizada" 96 , que lograba interrogar al sujeto neutro y masculino de los partidos de la izquierda revolucionaria:

la verdad que en el sector donde yo me ubique con el MIR (...) habían muchas mujeres que eran miembros del MIR y que tenían cargos de responsabilidad y que eran súper comprometidas (...) a mí me parece normal que ella fuese la jefa del MIR porque era la que yo veía que tenía más capacidades que el resto del grupo que estábamos trabajando. No me pareció en ese momento tan, el tema de género... el tema de mujeres dentro de la política, sino que era normal que ella fuese nuestra jefa

A su vez, la reafirmación del liderazgo de la jefa de la Unidad Campesina en la rememoración de María, es consistente con lo planteado por Ruíz sobre la "idea de excepcionalidad" y de "encarnación del militante ideal", puesto que dicha mujer dirigente representa valores y conductas ejemplares como militante que daban cuenta de su "inteligencia, oratoria magnífica, coraje y entrega total a la causa revolucionaria", por lo que se afirma que el ejemplo de los dirigentes "modelaba la identidad de los militantes, tanto o más que los cursos y manuales de formación política". Ello era así también para el caso de las militantes mujeres. De acuerdo a lo anterior, es posible comprender el rol de los y las dirigentes como militantes que actuaban "como intermediarios entre el proyecto y el conjunto de los militantes", puesto que "condensaban en sí mismos los atributos que la comunidad considera deseables" 97 .

Ahora bien, ¿a qué se dedicaba la Unidad Campesina operativa en el sector de Los Andes-Quillota? María indica los trabajos que desempeñaban en el periodo comprendido entre los años 1971-1972:

la formación y el acercamiento a los campesinos MCR que había en el sector (...) y lo que más trabajamos era entregar "El Rebelde" y entregar propaganda sobre el MCR en los distintos grupos campesinos (...) más que nada trabajamos con los "Cristianos por el Socialismo", que eran un grupo de curas que estaban ubicados en Los Andes. Había una casa donde vivían curas que se habían incorporado como curas campesinos (...) entonces con ellos trabajamos más que nada (...) las bases campesinas estaban, estaban siendo trabajadas por los profesionales y la gente de INDAP y la CORA (...) nosotros nos poníamos de acuerdo en objetivos, en determinados objetivos y en esos objetivos íbamos avanzando (...) salíamos a apoyar las distintas proyecciones de expropiación campesina y con algunos sindicatos que todavía habían de los campesinos que no formaban asentamientos (...) nos juntábamos e íbamos a los distintos lugares donde entregábamos información sobre la Reforma Agraria y donde eh... también apoyábamos en este caso a los fundos que estaban tomados para poder acelerar que se iniciase la expropiación y que se pudiese incorporar al primer paso de la Reforma Agraria que eran los asentamientos.

En ese punto, se reafirman la radicalidad política asumida en conjunto por el

${ }^{97}$ Ruiz, op. cit., 174-175. 
Movimiento Campesino Revolucionario y los Cristianos por el Socialismo, con la finalidad de colaborar con los sindicatos campesinos en la producción socialista de los asentamientos o las expropiaciones en la zona, debido a que, como señala María:

las tierras del sector de acá del Valle de Aconcagua estaban siendo tan mal explotadas y con tan baja producción que lo que correspondía era entregársela a los campesinos para que la producción pudiese ser todas las tierras cultivadas (...) donde estaban las mejores tierras del país eran de una bajísima productividad, porque no estaban todas sembradas (...) los dueños de los fundos vivían todos en Santiago, solo iban a veranear al campo y la gran proporción de las tierras estaban casi abandonadas y por lo tanto a nosotros nos parecía que si correspondía la Reforma Agraria, porque no era que nos estuviesen diciendo en una propaganda ni en un documento, sino que era lo que nosotros veíamos cotidianamente y el abandono el que estaban los sectores campesinos que no tenían absolutamente ningún tipo de posibilidad de estudio ni de salud ni de vivienda, porque todas las viviendas pertenecían a los fundos

Posteriormente, cuando María pasa a trabajar a Quillota-La Calera, el trabajo político de los campesinos se empieza a articular más con el de los obreros, lo que equivale al proyecto político del MIR identificado como la Unidad Obrero-Campesina. Se trataba de que los frentes de masas del partido -Movimiento Campesino Revolucionario y Frente de Trabajadores Revolucionarios- fueran construyendo un movimiento popular que diera sustento al quehacer revolucionario del MIR en la esfera político-militar. En ese sentido es importante señalar que, a comienzos del gobierno de la Unidad Popular, la fábrica textil Rayón Said -principal fuente de trabajo para Quillota en su momento- fue tomada por sus trabajadores, quienes reclamaban contra los bajos sueldos, malas condiciones de trabajo, discriminación de salarios para la mujer, contratación de menores de edad, entre otros problemas. En ese contexto, pidieron al gobierno que la fábrica fuese intervenida y pasada al área social. Durante la toma los obreros continuaron trabajando en sus tres turnos para demostrar que la fábrica en sus manos podía seguir produciendo, y su sindicato -con una fuerte presencia del MIR- tomó el control de la empresa. Así, el gobierno decidió pasarla al área social de producción, ganando varias mejoras reivindicativas, y el consecuente aprendizaje de una experiencia de lucha y organización profundamente significativa para el movimiento popular. Junto con ello, los obreros formaron una cooperativa de vivienda, solucionando de forma autónoma el problema de habitabilidad, en lo que hasta hoy se conoce como la población "Santa Teresa" de Quillota. María nos comparte sobre esta sinergia emergente en el año 1973:

seguimos estando vinculadas con los movimientos campesinos, con los distintos sindicatos y con la unidad, la base campesina pero también allí, al llegar a Quillota, es una ciudad se incorpora otro elemento importante que era para el movimiento político de ese tiempo, que es el movimiento obrero y dado que Quillota es una ciudad que tiene la característica de ser agrícola e industrial entonces allí se plasma, lo que dentro de las políticas del MIR, es lo que se hablaba de la Unidad Obrero-Campesina y en ese, en esa conocimiento de esa unidad nosotros tomamos, nos sumamos al trabajo de la Rayón Said que estaba en el FTR [Frente de Trabajadores Revolucionarios] que era un movimiento obrero tremendamente fuerte y nosotros nos sumamos a ellos, nosotros no 
íbamos allí a dar nosotros la línea política, sino que nosotros nos sumábamos al trabajo que tenían los obreros que eran los protagonistas (...) se hacían reuniones con los dirigentes campesinos y esa es la práctica que hacíamos lo que se llamó la Unidad Obrero-Campesina y que se planteaba un programa tanto para el campo como tanto para la ciudad... sin olvidarnos que en este caso la Rayón Said era quien tenía el protagonismo del movimiento obrero en Quillota, también estaban las industrias conserveras que era las que se relacionaban directamente con los productos del campo (...) Entonces el trabajo allí se hizo en función de eso, apoyando la Reforma Agraria se hacían manifestaciones, bajaban los campesinos con los tractores de los distintos lugares de trabajo se juntaban en las concentraciones con los obreros de la Rayón Said, de las otras industrias y se planteaban, se hablaba respecto al movimiento popular, a las exigencias que tenía el programa de Allende y a alguna forma de demostrar que se estaba trabajando en conjunto.

A partir de dicha experiencia, el MIR en Rayón Said comienza a solidarizar y traspasar experiencias a otros trabajadores del territorio local. En el año 1973, los frentes de masas del MIR se toman la fábrica de Cemento Melón de la Calera y la Conservera Bozzolo (Centauro) ubicada camino a Limache. Con ello parte un incipiente proceso de formación de "Cordones Industriales", con vistas a la construcción de espacios de poder popular y control comunitario en la zona de Quillota, el cual fue apoyado además por pobladores y estudiantes. Por supuesto que, a partir del golpe militar de 1973, Quillota sufrió una fuerte represión política que desactivó el proceso de construcción del campo popular y, con ello, el quehacer de la Unidad Obrero-Campesina, siendo Rayón Said una de las tantas empresas intervenidas y desarticuladas. En ese contexto político-social, María señala que dicha experiencia fue muy valiosa para ella, dando cuenta de un aprendizaje partidario que se hacía en el conocimiento de todos los frentes con los cuales se estaba trabajando. De ahí que ella empezó a vincularse a otras prácticas militantes:

tareas y actividades más estratégicas que tenía que ver también con el proyecto político y con poder cuajar este camino que nosotros pensábamos que íbamos trabajando hacia el socialismo.

La vinculación que hace María con los cordones industriales no es menor porque permite entender que la militancia en el MIR atravesó efectivamente diferentes frentes en pos de el futuro que los movilizaba. En tal sentido, conviene tener en mente lo que ha señalado Gaudichaud respecto de las disputas por el pasado.

La historia del "poder popular" y de los Cordones Industriales necesita salir de la mitología: no fueron ni "soviets a la chilena" como lo afirma todavía una parte de la izquierda extraparlamentaria, ni un peligroso ejercito paralelo tal como ha intentado hacer creer la dictadura. Lo que sí fueron, son gérmenes de poder dual y de una sociedad futura en construcción, que no logró desarrollarse en el contexto del Chile de principios de los sesenta. Sin embargo, esta experiencia muestra claramente el camino que podría tomar la democratización real de nuestras sociedades, siguiendo el camino del control democrático de los medios de producción y de la autogestión. La herencia de luchas sociales tan ricas no puede ser un simple tema de investigación académica: necesita también salir del olvido, la amnesia controlada y insertarse en la actual 
"batalla de la memoria" "98.

El derrocamiento de la experiencia de la Unidad Popular y la insuficiencia de la política de resistencia por los revolucionarios frente a la intervención militar se encuentra ampliamente desarrollado ${ }^{99}$. El MIR habría logrado reunir a su Comisión Política, pero no así a su contingente de fuerzas armadas, por lo que resistió esporádica y focalizadamente a la contrainsurgencia, para luego ordenar en definitiva el repliegue de los cuadros del partido a la clandestinidad. La represión y tortura de su militancia ${ }^{100}$ cerrarían dicha etapa ascendente del proceso de construcción del "poder popular".

Para terminar, nos parece importante señalar que María sobrevivió a la prisión política y la tortura, durante toda la dictadura participó en diferentes formas de resistencia, y tras el cambio de régimen político continúa participando en múltiples colectivos y organizaciones sociales y políticas vinculadas a las luchas por la memoria y la defensa de los derechos humanos, organizaciones feministas y una serie de otras movilizaciones políticas contra el orden neoliberal.

\section{Cierre}

Después de haber explorado, desde un relato de vida, la trayectoria política seguida por una mujer militante del Movimiento de Izquierda Revolucionaria en el marco de la Reforma Agraria durante el gobierno de la Unidad Popular (1970-1973), pudimos aproximarnos a comprender el surgimiento de una Unidad Campesina operativa del frente de masas en los territorios locales del Valle del Aconcagua en la región de Valparaíso. A partir de estos resultados, todavía preliminares en el contexto de una investigación mayor, sobre las articulaciones entre género y memoria, nos interesa dejar planteadas algunas ideas sobre cómo aquí se pueden observar tres memorias sociales subalternas que remiten a la experiencia militante, femenina y local.

En primer lugar, creemos que el relato de María nos permite visibilizar cómo la práctica militante es reconstruida desde el presente. Si las memorias sociales sobre la dictadura han tendido a relevar la posición de víctima y de derrota, de quienes experimentaron la persecución política y el terrorismo de Estado, cuando interrogamos por la trayectoria política el pasado se extiende hasta finales de los años 60 , y no solo a lo acontecido durante la dictadura. Con la ampliación de ese marco temporal, el haber sido protagonista de procesos de transformación profunda, desde la militancia en proyectos revolucionarios, se vuelve un eje central para la reconstrucción de la historia personal y social.

\footnotetext{
${ }^{98}$ Franck Gaudichaud, La Central Única de Trabajadores, las luchas obreras y los Cordones Industriales en el período de la Unidad Popular en Chile (1970-1973). Análisis histórico crítico y perspectiva, Santiago, 2013, 22.

${ }^{99}$ Ignacio Vidaurrázaga, Martes once: la primera resistencia, Santiago, LOM Ediciones, 2013.

100 Cristián Pérez, “Años de disparos y torturas (1973-1975). Los últimos días de Miguel Enríquez”, Estudios Públicos, 96, Santiago, 2004, 325-382.
} 
La experiencia narrada por María, como militante del MCR, nos permite comprender de mejor manera el universo de significaciones y los alcances que tuvo un proyecto político revolucionario en las formas de subjetivación política. Al respecto, destaca cómo la memoria militante pone en cuestión la separación entre la vida pública y privada, porque la transformación social que orientaba a los proyectos políticos se funde con narraciones de la vida cotidiana, a familia, los valores, la amistad y los lazos afectivos que unían a los militantes. Es por ello que una organización de base, como "la Unidad Campesina" que nos describe María, superaba con creces la condición de agrupación de agentes reunidos solo por finalidades ideológicas, había, como ella relata, una "necesidad de estar juntos".

A su vez, la militancia es rememorada desde posiciones de sujeto fuertemente protagónicas, pero en un sentido colectivo más que individual. Se trata más bien de comunidades de vida donde se entrelazaron afectos, ideas, razones y pasiones, lo privado y lo público. Por cierto, como suele suceder en la rememoración de vidas comunitarias, las rememoraciones de María no incluyen conflictos, tensiones ni sinsabores, algo que difícilmente estuvo ausente.

Además, y coincidiendo con trabajos análogos sobre la rememoración de las militancias de mujeres revolucionarias en Argentina, como el citado trabajo de Alejandra Oberti, el relato de María también reproduce memorias que muestran que la militancia en la nueva izquierda estuvo marcada por la lógica sacrificial, donde había que renunciar o posponer lo individual por el proyecto político revolucionario y donde operaba una suerte de borramiento del sí mismo en el colectivo.

Con todo, es en la memoria militante donde más sentidos del presente aparecen organizando el recuerdo, marcado por una comparación constante entre cómo se vivía la política y la preocupación por lo colectivo antes y ahora. Desde allí se visibilizan más fuertemente los diagnósticos críticos con el Chile de la postdictadura.

En segundo lugar, este relato permite poner en primer plano la forma en que las mujeres vivieron estos procesos de transformación radical a finales de los años 60' y cómo, tras experimentar la represión política, reconstruyen sus experiencias situando a la norma de género como algo relevante.

Aquí conviene señalar que no sólo ser mujer militante en la izquierda revolucionaria de esos años fue en sí misma una práctica subalterna, sino que las memorias sociales hegemónicas sobre el pasado reciente tienden a reproducir la subalternidad al invisibilizar las dimensiones de género presenten en los trabajos de la memoria.

En un sentido, cabe destacar cómo las mujeres al narrar sus trayectorias políticas parten casi siempre refiriéndose a sus familias de origen, ya sea por oposición a la postura de los padres o en tanto ellas asumían los compromisos políticos de sus familias como parte de un legado. Más aún, la narración de la trayectoria política suele partir recordando las 
formas de socialización política familiar, algo que, como señalamos, no ocurre tanto en los varones. Por otra parte, María relata cómo su decisión de irse a trabajar al campo en su práctica profesional como estudiante universitaria, situación que la inicia en la militancia política, estuvo marcada por las posibilidades de autonomía que ello le daba con relación a la vigilancia familiar. En otras palabras, la familia de origen marca de múltiples formas a las mujeres jóvenes que a finales de los años sesenta rompieron con el modelo de género tradicional. Más aún, ello parece condicionar un recuerdo de sí mismas donde se relatan como niñas y adolescentes diferentes a sus pares, más interesadas en el acontecer nacional, en la cultura, en informarse. No se trata de afirmar que las mujeres recordemos de manera diferente por ser mujeres sino de recalcar que las posiciones sociales que ocupamos las mujeres, posiciones de subalternidad, son relevantes a la hora de reconstruir el pasado.

No obstante, al interrogar las memorias desde una perspectiva de género también hay que analizar cómo el género hegemónico se reproduce o se desafía al hacer memoria. Aquí cobra sentido indicar que pese a la reflexividad de género que María expone al relatar cómo le impactaron las condiciones de miseria que afectaban especialmente a las mujeres campesinas, ellas, las campesinas, luego desaparecen de su discurso. María relata cómo sus convicciones ideológicas ligadas a su participación en el MIR, así como su compromiso estudiantil como trabajadora social formada en una tradición crítica, la llevaron a querer vivir como los campesinos, y desde ahí a actuar protagónicamente en los procesos de disputa por la tenencia de la tierra, la sindicalización campesina y las luchas por la vivienda asociadas a la Reforma Agraria y la Unidad Popular. Sin embargo, allí sólo aparecen los campesinos varones. Sus memorias personales encarnan de este modo memorias sociales dominantes que ponen en primer plano a los obreros y campesinos como sujeto masculino. Son memorias que, tal como ha mostrado Tinsman, subestiman o invisibilizan las formas en que procesos como la Reforma Agraria afectaron las relaciones de género. No es responsabilidad de María, sin duda, pero su relato permite interrogarnos por los silencios que las militancias de la izquierda también reproducen.

Con todo, creemos que un hallazgo relevante de esta investigación es visibilizar el rol protagónico de las mujeres del MCR. Como señalamos, María da cuenta de cómo en la Unidad Campesina participaban tres mujeres, incluyendo a la jefa de la Unidad. Sobre este liderazgo femenino, la propia María resalta su excepcionalidad, dando cuenta de la idea sostenida por Ruiz, que nos permite comprender cómo los liderazgos en el MIR, al menos en sus rememoraciones, operan como ejemplos modeladores de conducta en una cultura política donde la disciplina, la entrega y el ejemplo en la acción cumplían un rol protagónico como ejes de la visión de mundo sostenida por el partido. Allí importa entonces recordar y documentar que hubo mujeres. Algo que debiera ser profundizado en futuras investigaciones.

Finalmente, el relato de María nos introduce en un tipo de memoria local que asumimos opera como una tercera forma de subalternidad. Ello porque en el Cono Sur las memorias dominantes han tendido a reconstruir un pasado casi siempre en clave nacional, y con una fuerte generalización de lo que ocurre en las capitales. La trayectoria de María 
permite remirar las transformaciones radicales al sistema tradicional campesino desde el territorio rural de la región de Valparaíso, y a su vez, relevan la importancia que tuvieron las estudiantes de universidades regionales en su imbricación con las luchas obreras y campesinas de localidades no centrales.

Por lo tanto, como proyecciones de este trabajo, creemos que hay que seguir investigando procesos que permitan comprender cómo se han invisibilizado las trayectorias políticas de mujeres militantes de organizaciones sociales y políticas de la izquierda revolucionaria, particularmente fuera de la capital, durante y después del período de la dictadura militar, desde un campo de acción subalterno en términos de identidades políticas, de género y territorio. El trasfondo de este problema supone que, en las disputas por las memorias oficiales, subalternas y subterráneas, este tipo de experiencias muestran lo que pasa entre diversas memorias subalternas: en este caso, la práctica política del militante (y no sólo de la "víctima"), la práctica política femenina (y no sólo la masculina) y la práctica política local (y no sólo la nacional). Lo anterior se justifica porque para el caso de sociedades como la chilena, que han vivido pasados traumáticos cargados de autoritarismo, violencia estatal y transformaciones estructurales forzadas, no es posible eludir las memorias sociales si queremos entender los modos en que desde el presente tales triples subalternidades siguen operando.

Referencias Bibliográficas

\section{Impresos}

Allende, Andrés Pascual, El MIR Chileno. Una experiencia revolucionaria, Argentina, Cucaña, 2003.

Alonso, Luís Enrique, La mirada cualitativa en sociología, Barcelona, Fundamentos, 1998

Amorós, Miguel, Miguel Enríquez. Un nombre en las estrellas. Biografía de un revolucionario, Santiago, Ediciones B, 2014.

Aspee Bou, Francisco José, Resistencia, voluntad y revolución en La Serena. Historias de vidas de actores sociales miristas en la ciudad de La Serena 1970 y 1975, La Serena, Tesis de Licenciatura, Universidad Pedro de Valdivia, 2012.

Baeriswyl, Fernando, Sartori, Ángel, Guzmán, José y Larenas, Francisco, Reforma Agraria y Desarrollo Rural en Chile. Mejoramiento de la Economía Social de los Predios, s.n., 2006.

Bengoa, José, El campesinado chileno después de la reforma agraria, Santiago, SUR, 1983.

SUR, 1990.

Haciendas y campesinos. Historia social de la agricultura en Chile, Tomo II, Santiago,

Bertaux, Daniel, Los relatos de vida. Perspectiva etno-sociológico, Barcelona, Bellaterra, 2005. 
Boldt, Kelley y White, Timothy, "Chilean Women and Democratization: Entering Politics through Resistance as Arpilleristas", Asian Journal of Latin American Studies, 24:2, 2011, 27-44.

Canales, Manuel, Metodologías de investigación social, LOM Ediciones, 2006.

Cardoso, Fernando Henrique y Falleto, Hugo, Dependencia y desarrollo en América Latina, Buenos Aires, Siglo XXI Editores, 1977.

Chonchol, Jaques, "La Reforma Agraria en Chile 1964-1973”, El Trimestre Económico, Santiago, 43:171, 1976.

Cid, Beatriz y Latta, Alex, "Agro-Ecology and Food Sovereignty Movements in Chile: Sociospatial Practices for Alternative Peasant Futures", Annals of the Association of American Geographers, 105:2, 2015, 397-406.

Coffey, Amanda y Atkinson, Paul, Encontrar el sentido a los datos cualitativos, Medellín, Editorial Universidad de Antioquía, 1996.

Cornejo, Marcela, Reyes, María José, Cruz, María Angélica, Villarroel, Nicolás, Vivanco, Anastassia, Cáceres, Enzo y Rocha, Carolina, "Historias de la Dictadura Militar Chilena desde Voces Generacionales", Revista Psykhe, 22:2, 2013, 49-65.

Crenzel, Emilio, La historia política del Nunca Más. La memoria de las desapariciones en la Argentina, Buenos Aires, Siglo XXI Editores, 2008.

Cruz, María Angélica, Articulaciones entre género y memoria social: los inicios de las trayectorias políticas femeninas antes del Golpe de Estado en Valparaíso y la pertinencia del "punto de vista" de las mujeres, Ponencia en II Seminario Internacional "Nuevos desafíos a los estudios sobre memoria en el contexto latinoamericano actual" organizado por la Red Interdisciplinaria de Estudios sobre Memoria Social (RIEMS), Mar del Plata, 26 y 27 de octubre, 2016.

de Paula Faleiros, Vicente, Trabajo social e instituciones, Buenos Aires, Humanitas, 1992.

del Pino, Ponciano y Jelin, Elizabeth, Luchas locales, comunidades e identidades, Buenos Aires, Siglo XXI, 2003.

Enríquez, Miguel, Con vista a la esperanza. Santiago, Escaparate Ediciones, 1998.

Fontaine, Arturo, La tierra y el poder: Reforma agraria en Chile (1964-1973), Santiago, Zig-Zag Ediciones, 2001.

Forstenzer, Nicole, "Ser feminista en el Chile actual: ambigüedades y dilemas de las reivindicaciones de igualdad de género" UMR 201 Développement et Sociétés, Université Paris I IEDES, 2013.

Gaudichaud, Franck, La Central Única de Trabajadores, las luchas obreras y los Cordones Industriales en el período de la Unidad Popular en Chile (1970-1973). Análisis histórico crítico y perspectiva, Santiago, 2013. 
Goicovic, Igor, "De la dura infancia, de la ardiente vida, de la esperanza... Un testimonio popular para la reconstrucción de nuestra historia reciente”, Última Década, 6, Viña del Mar, 1997.

, El internacionalismo proletario en el Cono Sur. La Junta Coordinadora Revolucionaria, un proyecto inconcluso, 2005.

, Los trabajadores al poder. El Movimiento de Izquierda Revolucionaria (MIR) y el proyecto revolucionario en Chile (1965-1994), Concepción, Escaparate Ediciones, 2016.

Gómez, Sergio, "Organización campesina en Chile: reflexiones sobre su debilidad actual”, Revista Austral de Ciencias Sociales, 6, 2002.

Guevara, Ernesto, El Pensamiento Revolucionario del "Che”, Seminario Cientifico Internacional. Intervenciones y debates, Buenos Aires, Editorial Dialéctica, 1988.

Halbwachs, Maurice, La memoria colectiva, Zaragoza, Prensas Universitarias de Zaragoza, 1968.

Hatibovic, Fuad, Sandoval, Juan y Cárdenas, Manuel, "Posiciones de sujeto y acción política universitaria: análisis del discurso de estudiantes de universidades de la Región de Valparaíso", Revista Última Década, 20:37, 2012, 111-134.

Hiner, Hillary, "Violencias soterradas, voces silenciadas. Discurso, violencia política y género en los Informes Rettig y Valech", Latin American Research Review, 44:3, 2009, 50-74.

\section{3:1, 2005, 3-22.}

"“They Dance Alone': Gender in the Chilean Transition to Democracy", Revista Anamesa,

Iglesias, Margarita, "Dictaduras personales. Dictaduras colectivas: mujeres militantes y movimientos sociales. Chile 1973-1999", Tania Medalla, Alondra Peirano, Olga Ruiz y Regine Walch, (eds.), Recordar para pensar. Memoria para la Democracia. La elaboración del pasado reciente en el Cono Sur de América Latina, Santiago de Chile, Ediciones Heinrich Böll Cono Sur, 2010, 221-229.

Jelin, Elizabeth, Los trabajos de la memoria, Buenos Aires, Siglo XXI Editores, 2002.

, "La conflictiva y nunca acabada mirada sobre el pasado", Marina Franco y Florencia Levín (comps.), Historia reciente. Perspectivas y desafíos para un campo en construcción, Buenos Aires, Paidós, 2007.

, "Subjetividad y esfera pública: el género y los sentidos de familia en las memorias de la represión", Revista Política y Sociedad, 48:3, 2011, 55-569.

Longoni, Ana, Traiciones, Buenos Aires, Norma Editorial, 2007.

Mack, Macarena, Matta, Paulina y Valdés, Ximena, Los trabajos de las mujeres entre el campo y la ciudad 1920-1982, Santiago, Centro de Estudios de la Mujer, 1986, 5-7.

Martínez, Fernando, Pensar al Che, La Habana, José Martí, 1989. 
Medel, Rodrigo, Movimiento sindical campesino en Chile (1924-2000), Santiago, CIPSTRA, 2013.

Middleton, Dave \& Edwards, Derek, Collective remembering, London, Sage Publications, 1990.

Mora, Claudia y Ríos, Marcela, “¿De Política de Representación a Política de Coalición?: Posibilidades de Movilización Feminista en el Chile Post-Dictadura”. Polis, Santiago, 8:24, 2009, 133-145.

Morán, José Manuel, "Feminismo, Iglesia Católica y derechos sexuales y reproductivos en el Chile post-dictatorial”, Revista Estudos Feministas, 21:2, 2013, 485-508.

Naranjo, Pedro et al. (ed.), Miguel Enríquez y el proyecto revolucionario en Chile. Santiago: LOM Ediciones, 2004, 101.

Oberti, Alejandra, Género, política y violencia. Vida cotidiana y militancia en las décadas del sesenta y setenta, Tesis para optar por el grado de Doctora en Ciencias Sociales, Buenos Aires: Universidad de Buenos Aires, 2011.

, "Las mujeres en la política revolucionaria. El caso del PRT-ERP en la Argentina de los años 70", Revista Internacional Interdisciplinar INTERthesis, 10:1, 2013, 6-36.

, Las Revolucionarias. Militancia, vida cotidiana y afectividad en los setenta, Buenos Aires, Edhasa, 2014.

Peirano, Alondra, "Revolución y lucha armada: ¿una relación necesaria? El Movimiento de Liberación Nacional-Tupamaros y el Movimiento de Izquierda Revolucionaria en sus inicios (19651973)", Revista Encuentros Latinoamericanos, 3:9, 2009, 3.

Pelieraki, Eugenia, ;La revolución ya viene! El MIR chileno en los años sesenta, Chile, Santiago, LOM Ediciones, 2014.

Pérez, Cristián, “Años de disparos y torturas (1973-1975). Los últimos días de Miguel Enríquez”, Estudios Públicos, 96, Santiago, 2004, 325-382.

Pollak, Michael, Memoria, olvido, silencio, Buenos Aires, Al Margen, 2006.

Portelli, Alessandro, La orden ya fue ejecutada. Roma, las Fosas Ardeatinas, la memoria, Buenos Aires, Fondo de Cultura Económica, 2004.

Reyes, María José, Cruz, María Angélica y Aguirre, Félix, "Los lugares de memoria y las nuevas generaciones: Algunos efectos políticos de la transmisión de memorias del pasado reciente de Chile", Revista Española de Ciencia Política, 41, 2016, 93-114.

Robles, Claudio, "Expansión y transformación de la agricultura en una economía exportadora. La transición al capitalismo agrario en Chile (1850-1930)", Historia Agraria, 29, 2003, 46-47. 
Rosenblitt, Jaime, La reforma universitaria (1967-1973), Santiago: s.n.; Carlos Huneeus, La reforma universitaria. Veinte años después, Santiago, CPU, 1988.

Ruiz, Olga, "Mandatos militantes, vida cotidiana y subjetividad revolucionaria en el Movimiento de Izquierda Revolucionaria de Chile (1965-1975)", Revista Austral de Ciencias Sociales, 28, 2015, 163-182.

Sapriza, Graciela, "Memorias de mujeres en el relato de la dictadura (Uruguay, 1973-1985). Violencia/cárcel/ exilio", Revista Telemática di Studi Sulla Memoria Femminile, 11, 2009, 64-80.

Stern, Steve, "De la memoria suelta a la memoria emblemática: Hacia el recordar y el olvidar como proceso histórico (Chile, 1973-1998)", en Elizabeth Jelin (comp.), Las conmemoraciones: Las disputas en las fechas “in-felices", Buenos Aires, Siglo XXI Editores, 2002, 11-33.

Tinsman, Heidi, La Tierra para el que la trabaja. Género, sexualidad y movimientos campesinos en la Reforma Agraria chilena, Santiago, LOM Ediciones, 2009.

Traverso, Enzo, El pasado, instrucciones de uso. Historia, memoria, política, Madrid, Marcial Pon, 2007.

Troncoso, Leyla e Piper, Isabel, "Género y Memoria: articulaciones críticas y feministas", Athenea Digital, 15:1, 2015, 66.

Valdés, Ximena y Rebolledo, Loreto, "Géneros, generaciones y lugares: cambios en el medio rural de Chile Central”, Polis, Santiago, 14:42, 491, 2015.

Vázquez, Félix, La memoria como acción social. Relaciones, significados e imaginario, Barcelona, Paidós, 2001.

Vergara-Camus, Leandro, "Rural Social Movements in Latin America: In the Eye of the Storm", Journal of Agrarian Change, 13:4, 2013, 590-606.

Vidaurrázaga, Ignacio, Martes once: la primera resistencia, Santiago, LOM Ediciones, 2013.

Vidaurrázaga, Tamara, “¿El hombre nuevo?: moral revolucionaria guevarista y militancia femenina. El caso del MIR”, Revista Nomadías, 15, 2012, 69-89.

Waldman, Gilda, "Voces vivas de la militancia femenina en los 60' y 70': tensiones de la subjetividad", Taller de Letras, 48, 2011, 87-89.

Walke, Francisco, La legislación laboral campesina, evolución y proposiciones, Santiago, Desarrollo Campesino SA, 1983.

Fuentes documentales

Affonso, Almino, Trayectoria del Movimiento Campesino Chileno, Santiago, ICIRA, Vol. I; 1970.

Allende, Salvador, Perspectivas sobre la reforma agraria, Chile, INDAP, 1972. 
Corporación de la Reforma Agraria, Reforma agraria chilena 1965-1970, Santiago, CORA, 1970.

MIR, Estatutos, 1965, s.n.

_. Programa, 1965, s.n.

_., Manual No 3: La base, Colección Miguel Enríquez, s.n.

___ Discurso del Secretario General del MIR a nombre de la Dirección Nacional, en Cautín el lunes $1^{\circ}$ de Noviembre de 1971 en Homenaje a Moises Huentelaf, héroe de la lucha campesina, Santiago (Biblioteca Nacional de Chile), 1971. 